بررسى آزمايشگاهى تأثير دبى جريان بر ميزان آبشستخى اطراف گروه يايههاى بِ زبر در حضور كودال برداشت مصالح رودخانهاى

\author{
رسول دانشفراز"، مريم ستاريان كرجآباد، بابكى علىنزاد و مهدى ماجدىاصل'

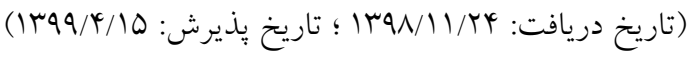

جكيده

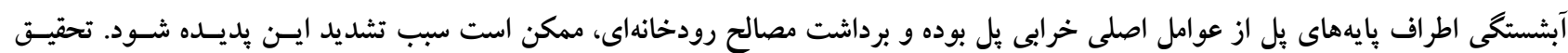

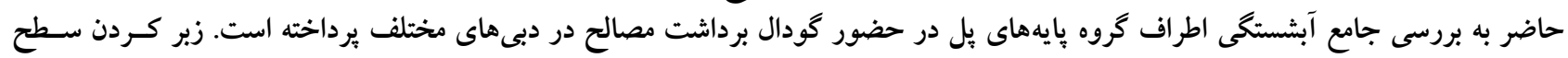

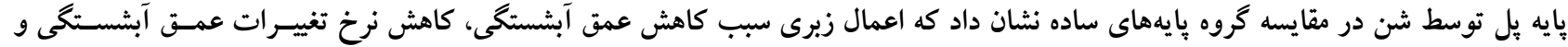

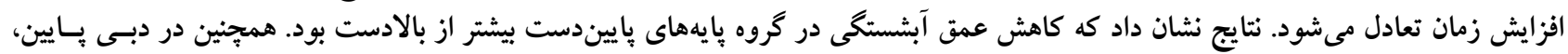

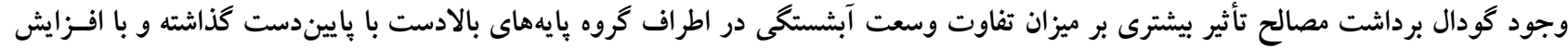

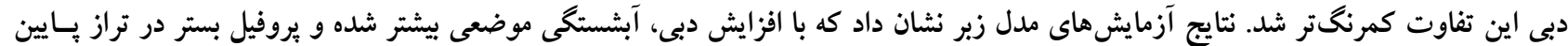

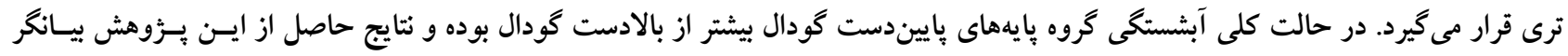

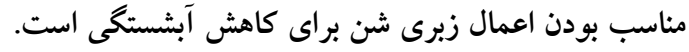

وازههاى كليدى: آبشستگى موضعى، گروه يايههاى بِ زبر، برداشت مصالح رودخانهاى، دبى جريان، بروفيل بستر 
مكانيسم آبشستخى شده و با افزايش ابعاد طوقه، زمان تأخير نيز

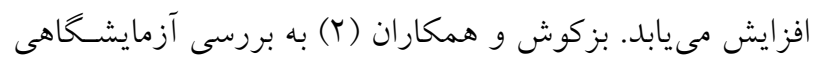

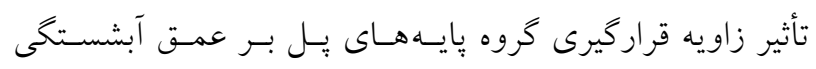

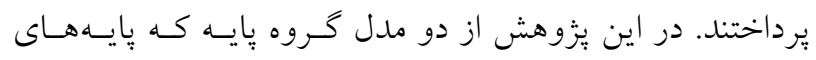

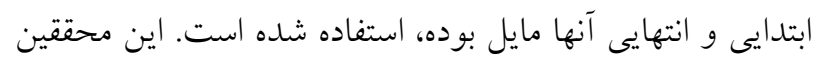

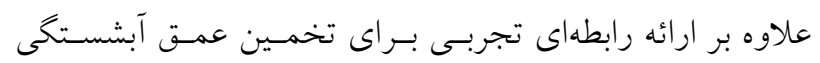

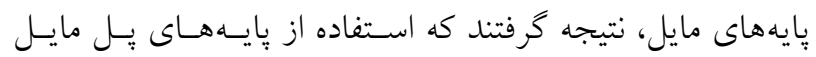

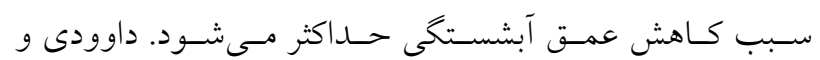

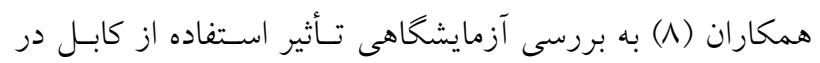

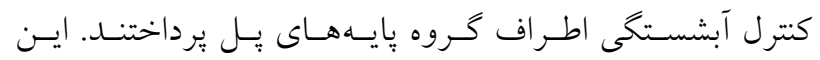

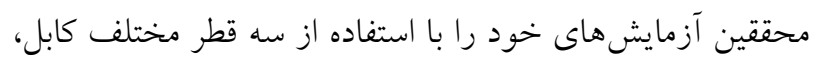
سه زاويه مختلف و سه دور رديف كابل، انجام دادند. تحقيقـات

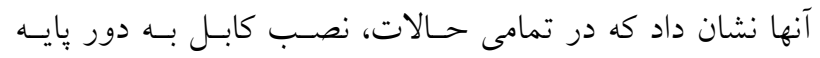

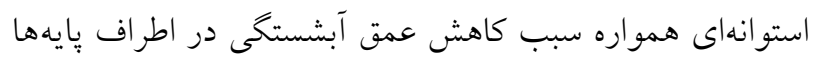

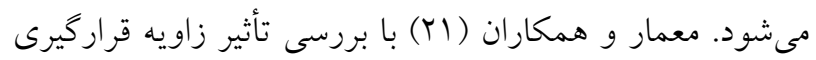

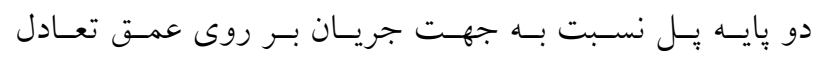

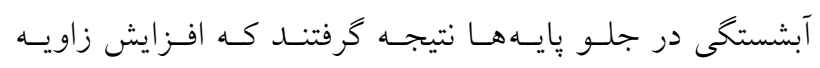

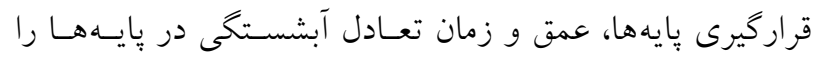

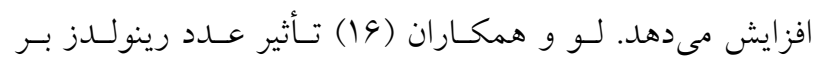

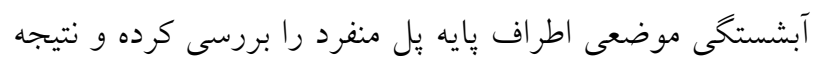

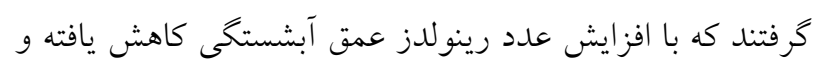

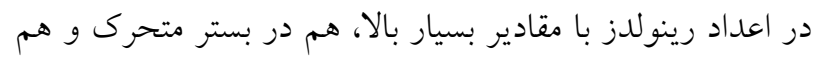

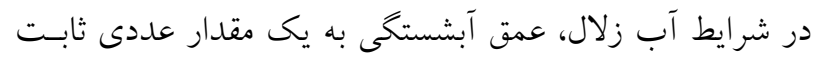

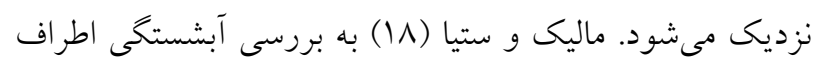

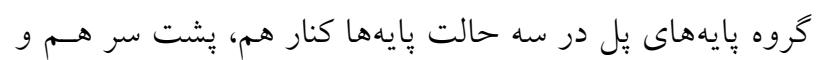

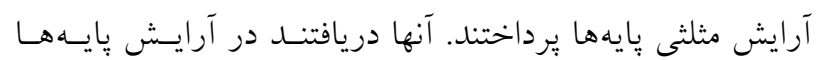

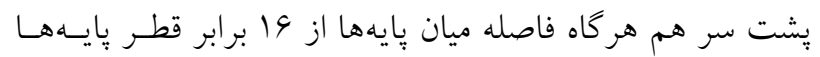

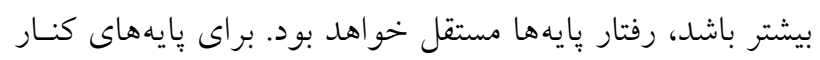

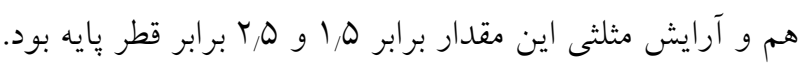

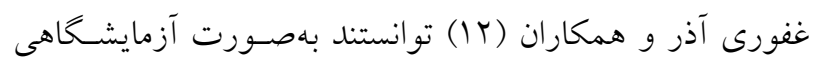
تغييرات زمانى و مكانى حفره برداشت مصالح را تحـت شـر ايط

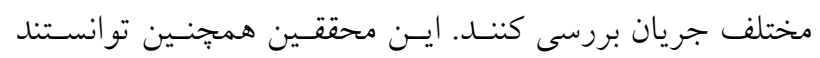

بديده آبشستخى اطراف بايههاى بِل از تأثير كذارترين بِديدههاى

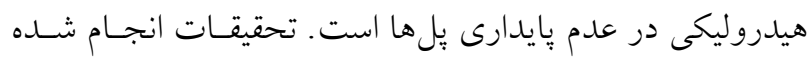

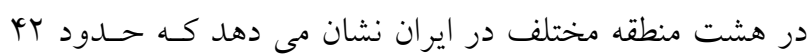

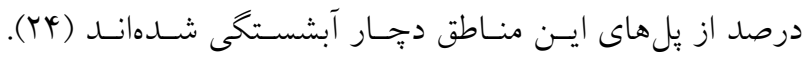

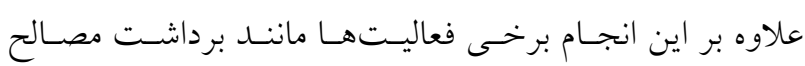

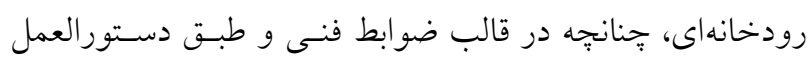

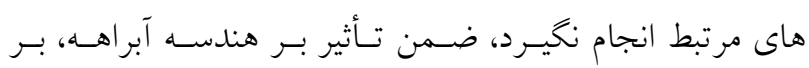

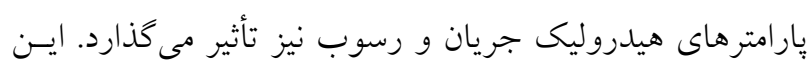

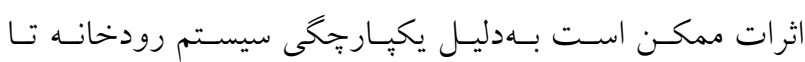

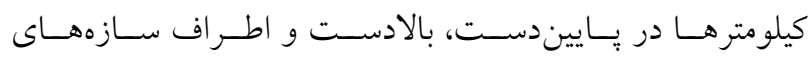

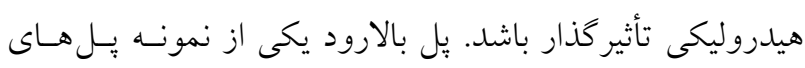
تخريب شده در اثر برداشت مصالح رودخانهاى در ايران است.

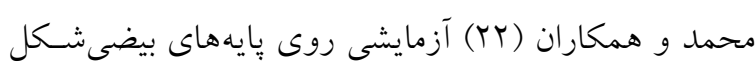

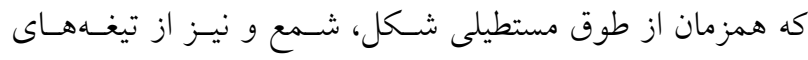

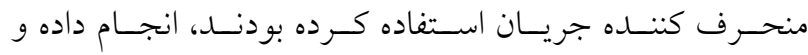
آبشستكى موضعى را به ميزان ه9 درصد كاهش دادند. كوئمو و

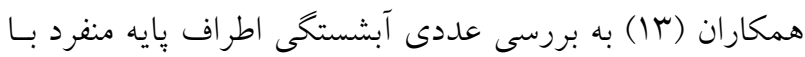

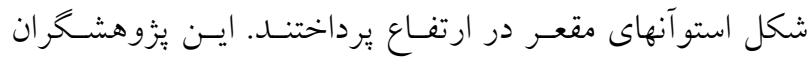

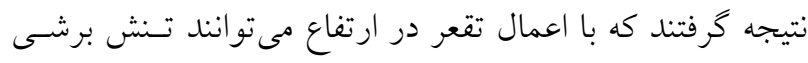

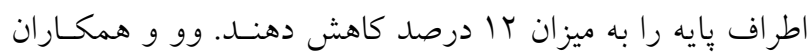

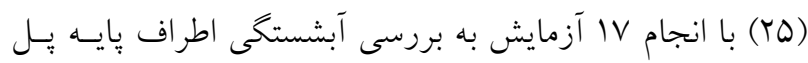

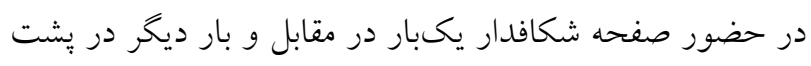

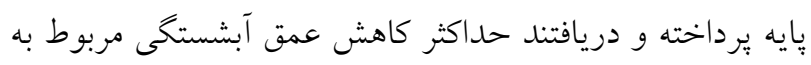

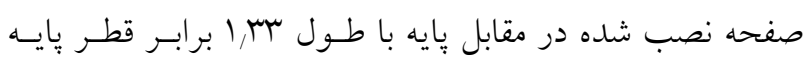

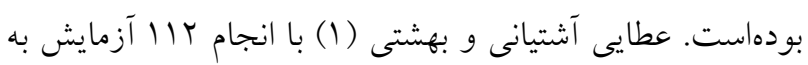

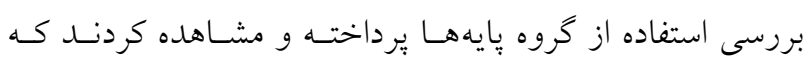

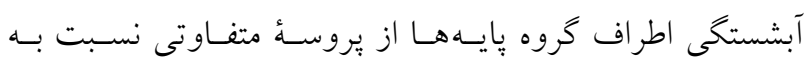

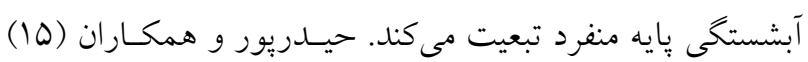

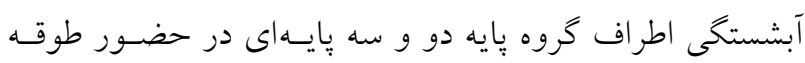

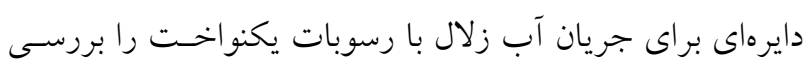

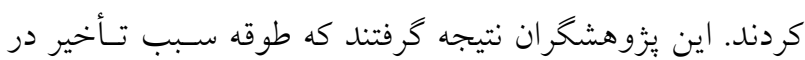


برداخته و نشان دادند كـهـ بـا تغييـر در قطـر ذره رسـوبى تـأثير جشميرى در استهلاك انرزى جريان ايجاد نشده است.

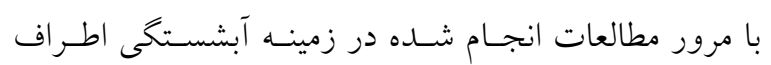

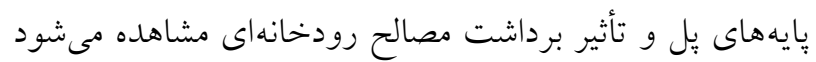

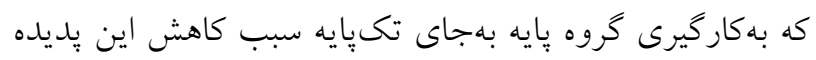

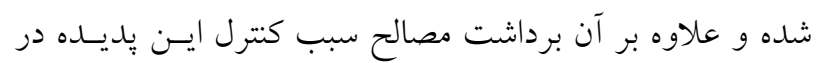

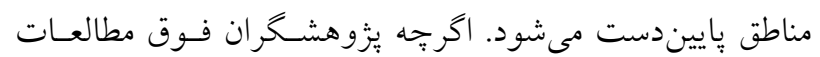

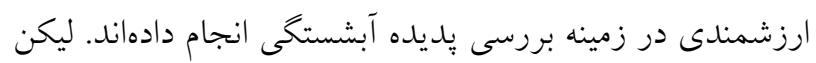

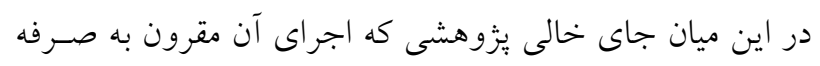

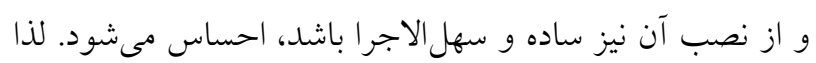

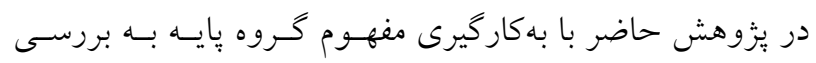

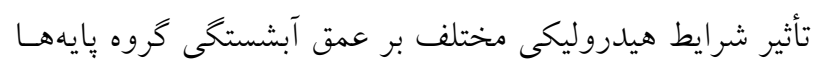

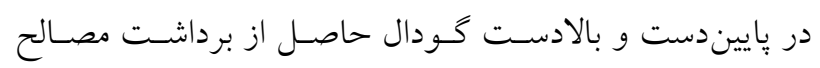

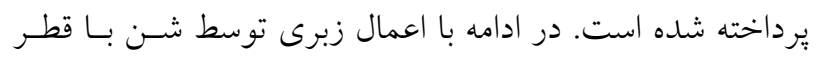

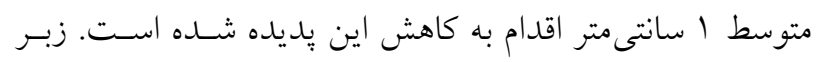

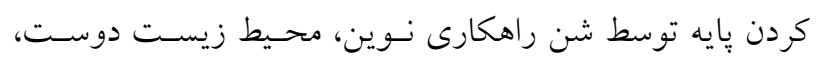

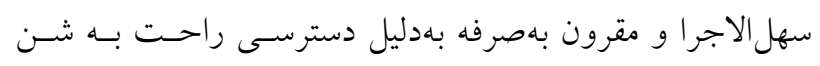

\section{مواد و روشها - ماد}

روش انجام آزمايش

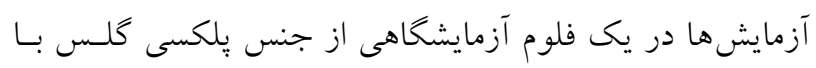

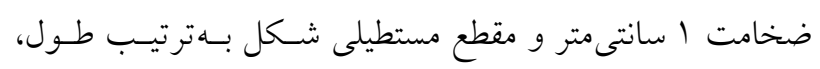

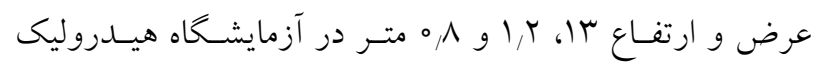

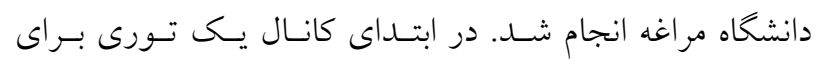

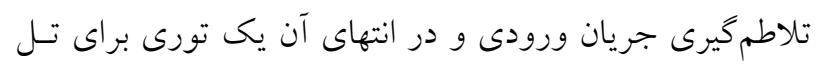
اندازى رسوبات شسته شده نصب شـــ يـك بسـتر رسـوبى بــه

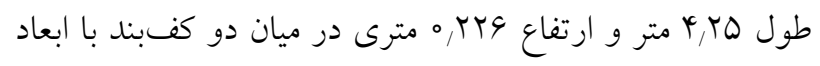

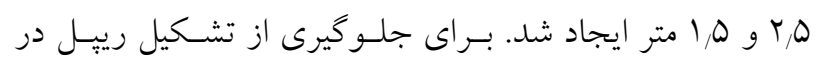

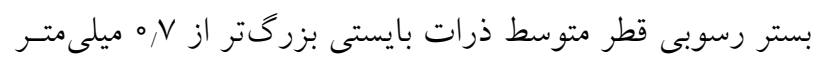

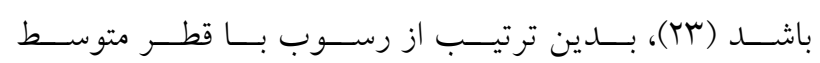

رابطهاى تجربى براى محاسبه حداكثر عمق آبشستخى و هم:جنين

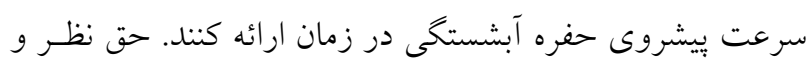

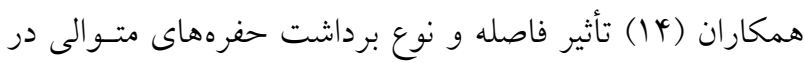

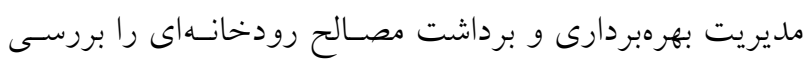

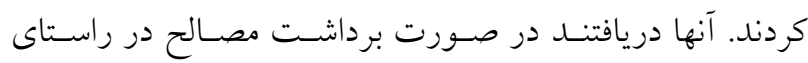

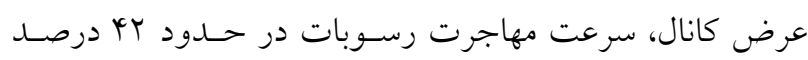

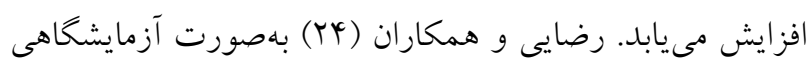

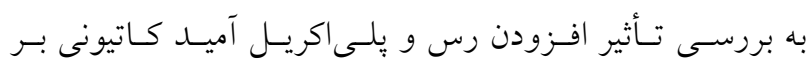

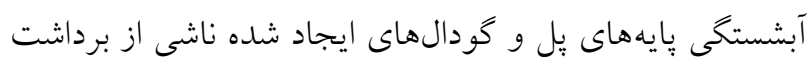

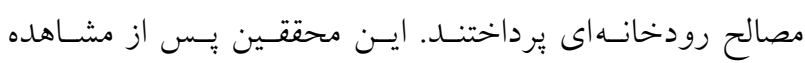

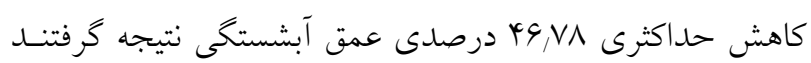

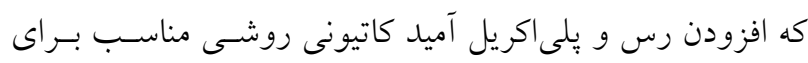

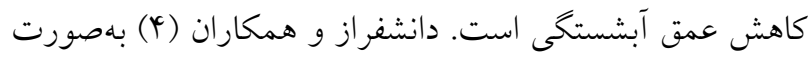

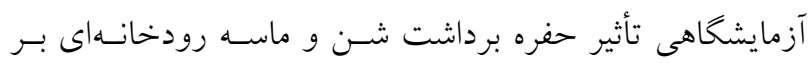

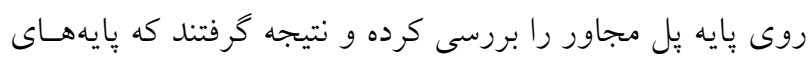

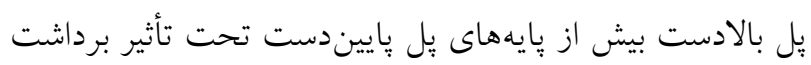

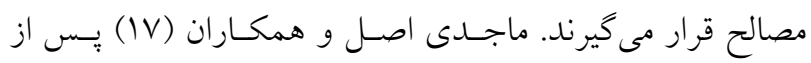

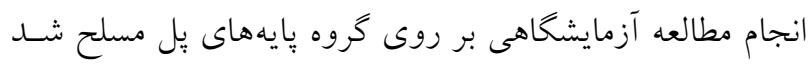

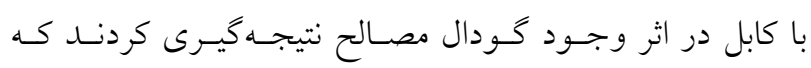

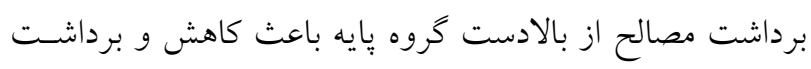

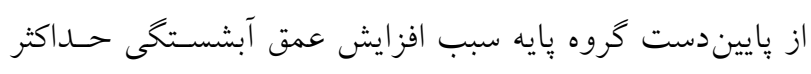

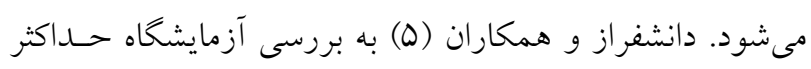

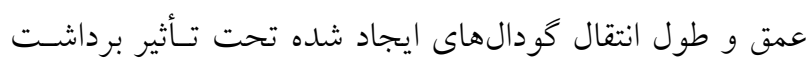

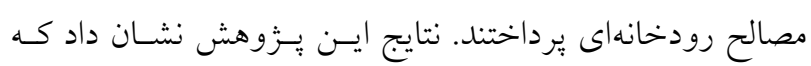

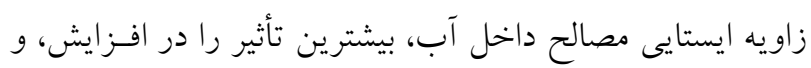

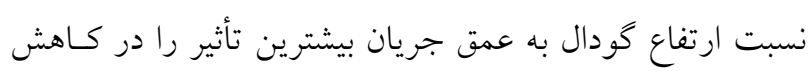

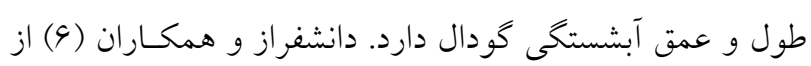

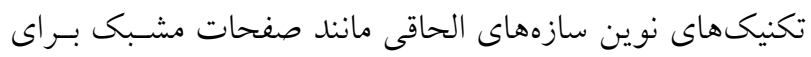

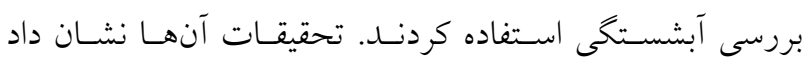

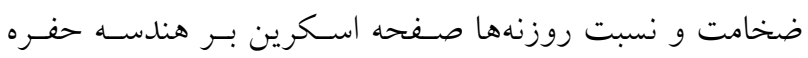

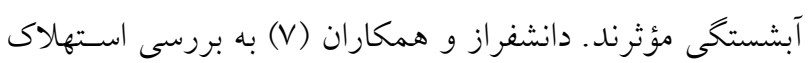

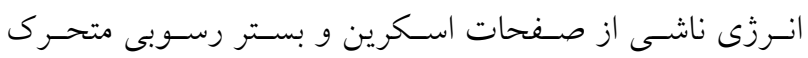



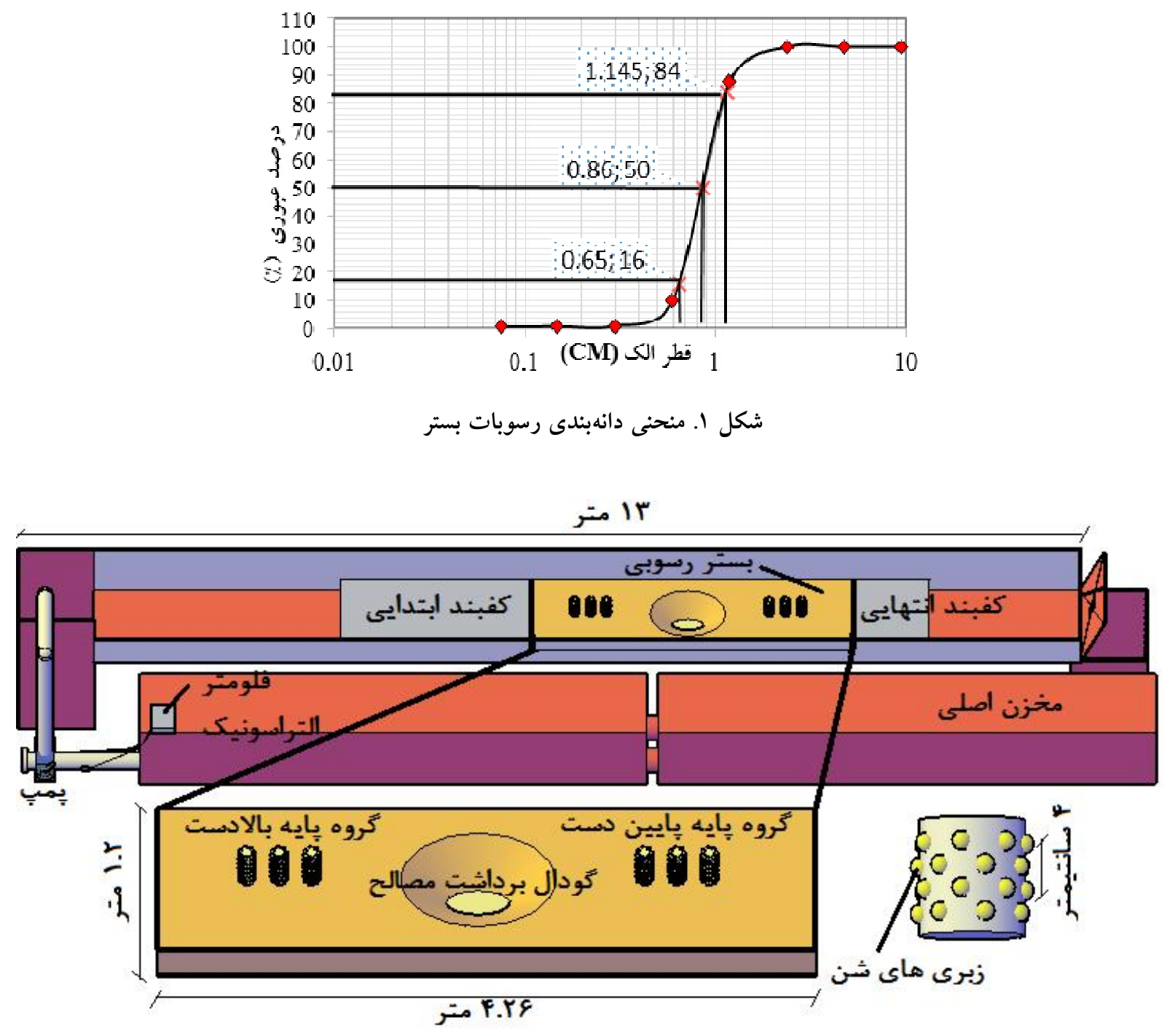

شكل r. نمادين كانال آزمايش، محل قرارگيرى بايهها و موقعيت گودال برداشت مصالح

اساس يافتهاى عطايى آثتيانى و بهشتى (1) براى بـروز اثـرات

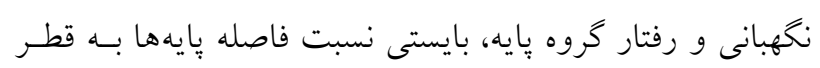

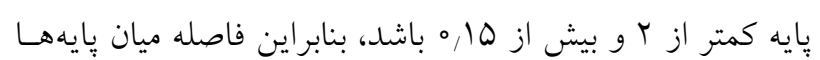

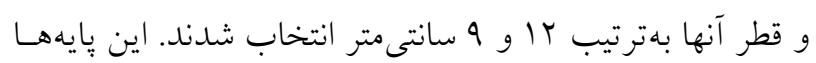

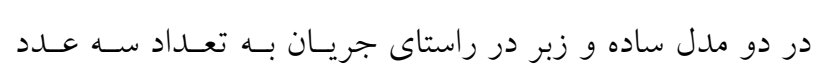

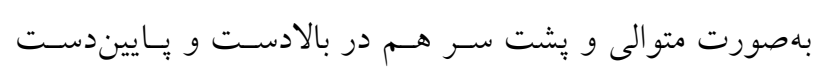

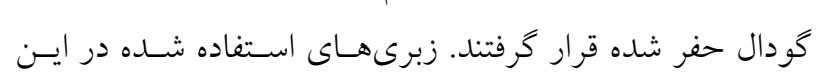

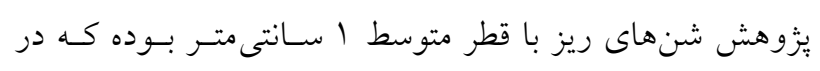

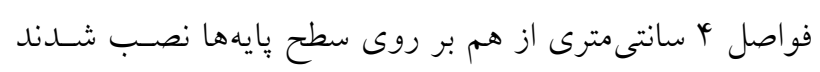

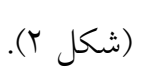

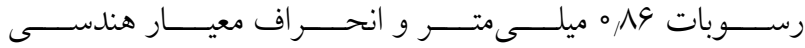
$\sigma_{g}=\sqrt{\frac{d_{84}}{d_{16}}}=1.32$

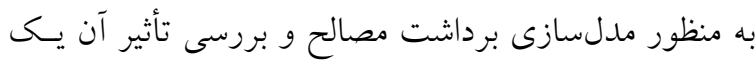

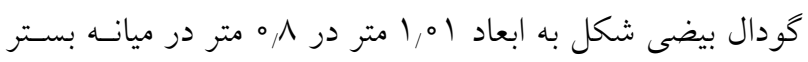

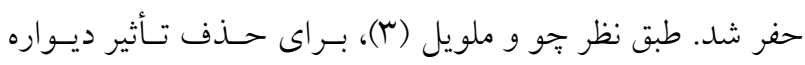

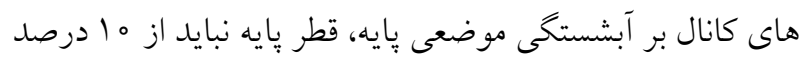

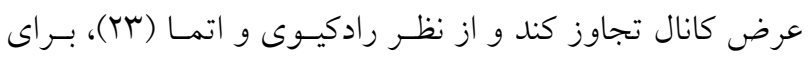

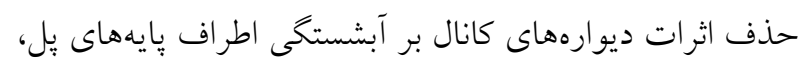

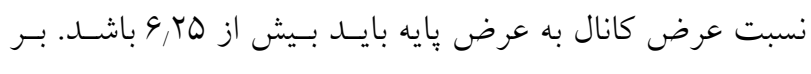


جدول ا. شرايط هيدروليكى آزمايش

\begin{tabular}{|c|c|c|c|c|c|c|}
\hline عدد فرود & قطر بايه (cm) & قطر متوسط ذرات (mm) & دبى جريان (L/s) & عمق جريان (m) & مدل پايه & آزمايش \\
\hline$\circ / T Q$ & 9 & $0 / 19$ & 10 & $0 / 09 \mu Y$ & زبر & 1 \\
\hline$\circ / T \Delta$ & 9 & $0 / 19$ & $\mu_{0}$ & $0 / 1090$ & زبر & r \\
\hline - TSQ & 9 & $0 / 19$ & ra & גואות & زبر & r \\
\hline $0 / T \Delta$ & 9 & $\circ / 19$ & 10 & $0 / 0 q_{\mu k}$ & ساده & r \\
\hline$\circ / T \Delta$ & 9 & $0 / 19$ & $r_{0}$ & $0 / 1090$ & ساده & 0 \\
\hline$\circ / T \Delta$ & 9 & $0 / 19$ & id & & ساده & 9 \\
\hline
\end{tabular}

ايجاد شده در وسعت حفره آبشستخى و همجنين تغييرات ايجاد

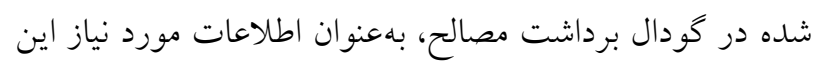

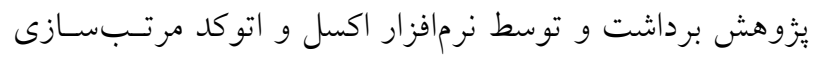

شدند.

آناليز ابعادى

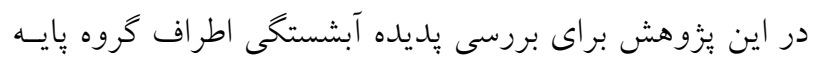

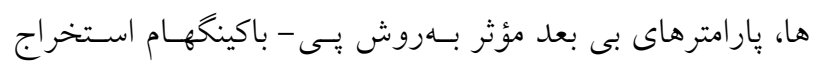

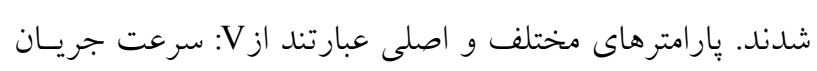

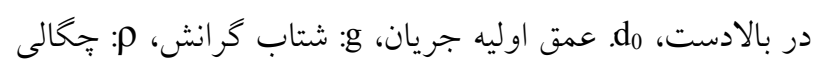

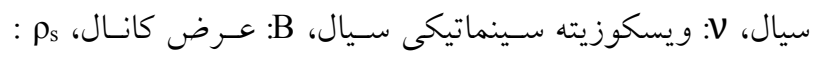

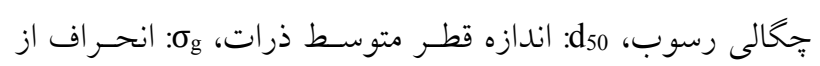

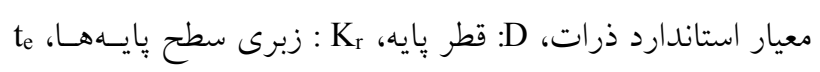

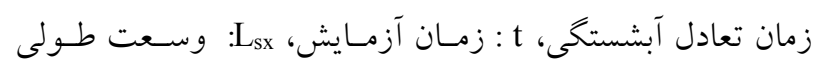

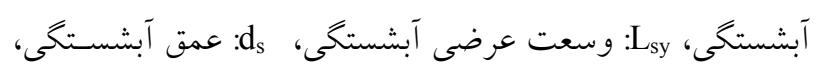

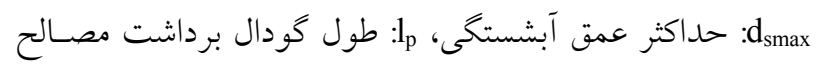

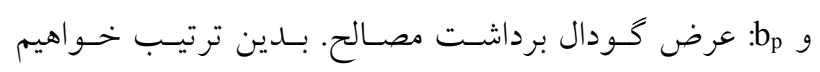
داشت:

$F=f\left(\begin{array}{l}V, d_{0}, g, \rho, v, B, \rho_{s}, d_{50}, \sigma_{g}, D, K_{r}, t_{e}, \\ t, L_{s x}, L_{s y}, d_{s}, d_{s_{\text {max }}}, l_{p}, b_{p}\end{array}\right)$

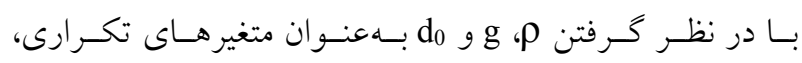

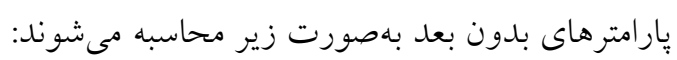

$\Pi=\mathrm{f}\left(\frac{\mathrm{V}}{\sqrt{\mathrm{gd}_{0}}}, \frac{v}{\mathrm{~d}_{0} \sqrt{\mathrm{gd}_{0}}}, \frac{\mathrm{B}}{\mathrm{d}_{0}}, \frac{\rho_{\mathrm{s}}}{\rho}, \frac{\mathrm{d}_{50}}{\mathrm{~d}_{0}}, \frac{\mathrm{D}}{\mathrm{d}_{0}}, \frac{\mathrm{K}_{\mathrm{r}}}{\mathrm{d}_{0}}\right.$,

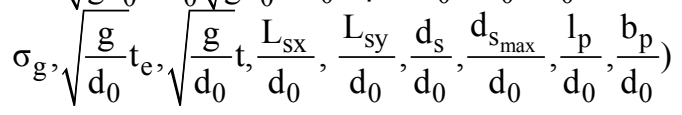

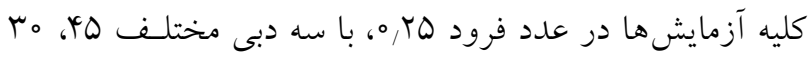

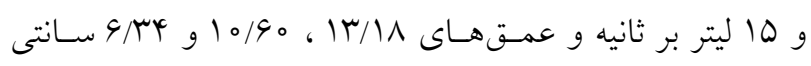

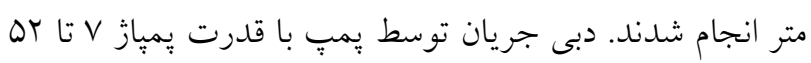

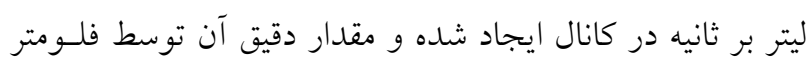

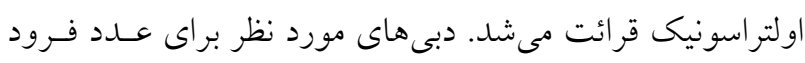

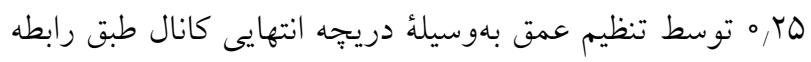

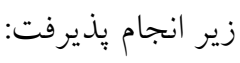

$\frac{\mathrm{Q}^{2} \mathrm{~T}}{\mathrm{gA}^{3}}=\mathrm{Fr}^{2}$

در معادله فوق Q دبى جريان بر حسب متـر مكعـب، T عـرض

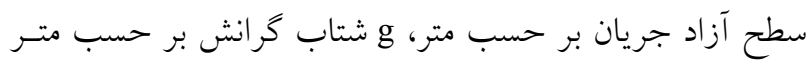

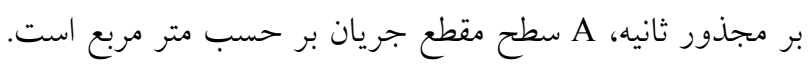

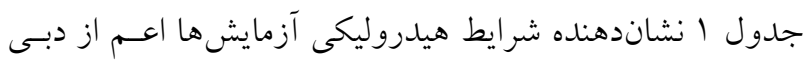

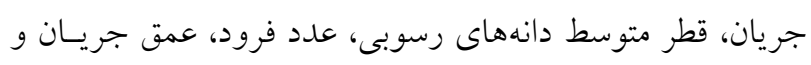
نيز انواع مدلهاى بايه يل است.

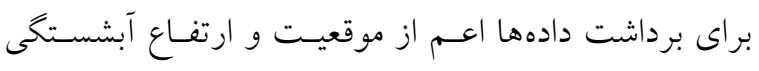

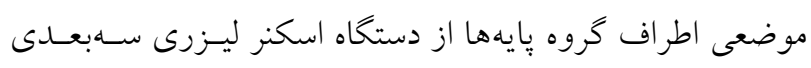

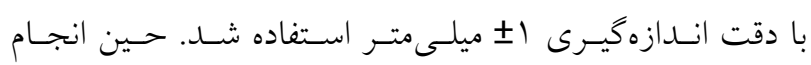

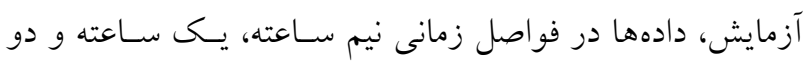

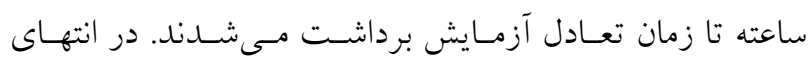

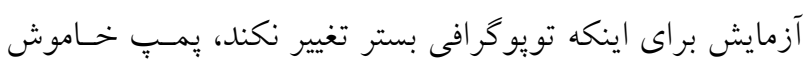

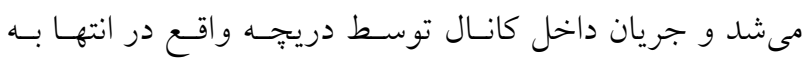

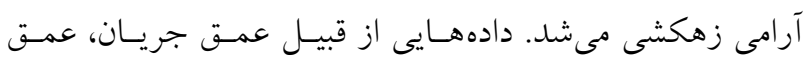

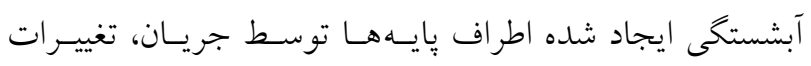


ناجيز بود. بدين ترتيب در اين موقع آبشستخى بـه تعـادل خـود

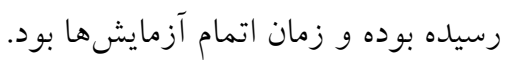

تأثير اعمال زبرى بر زمان تعادل و آبشستخى اطـراف گــروه يايه ها شكل r نمودارهاى تغييرات زمـانى عمـق آبشستــى در مقابـل

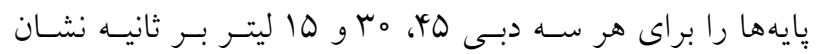

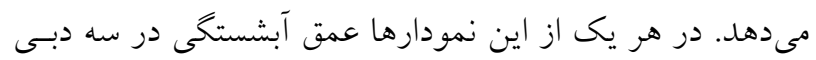

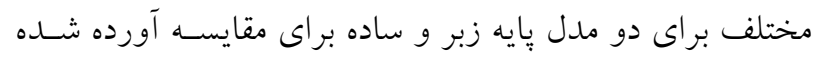

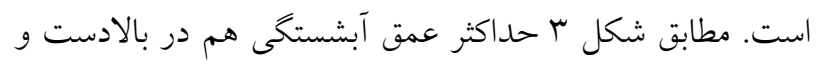

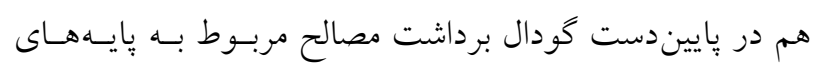

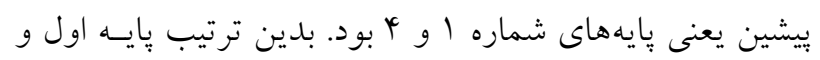
جهارم از اهميت ويزهاى نسبت به ساير بايهها برخوردار هستئنس.

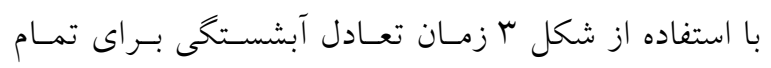

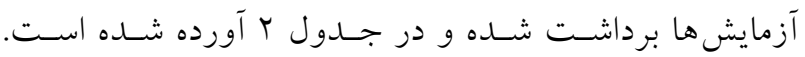

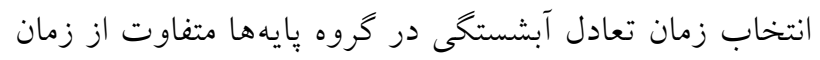

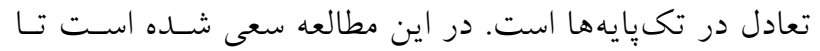

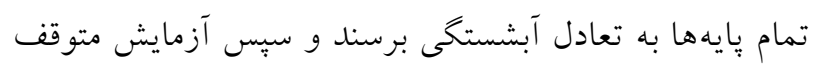

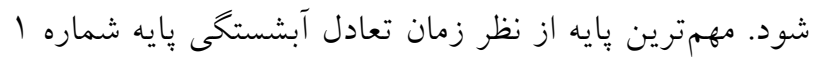

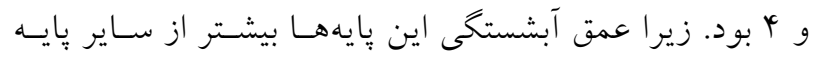

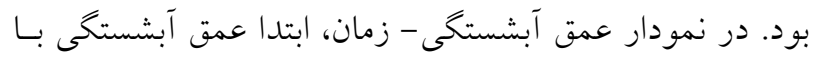

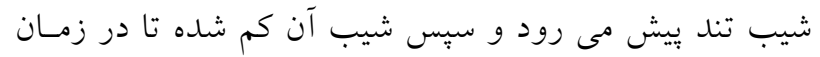
معينى شيب نمودار به افقى شدن مى گرايد كه اين زمان بيانخر

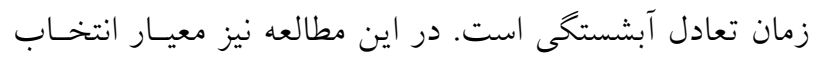
زمان تعادل افقى شدن روند نمودار عمق- زمان يا همان شكل

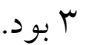
مطابق شكل بَ و جدول r اعمـال زبـــ سـبب افـزايش زمـان

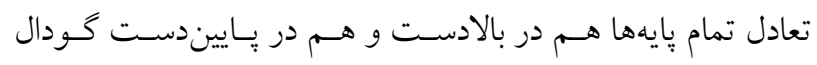

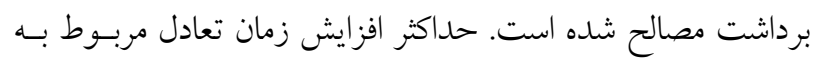

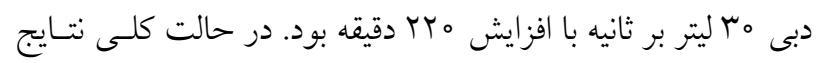

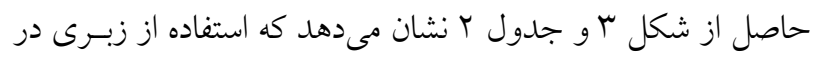

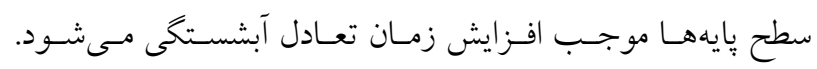

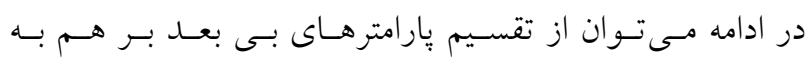
يار امترهاى بى بعد جديدترى دست يافت: $\Pi=f\left(\frac{\mathrm{Vd}_{0}}{\mathrm{v}}, \frac{\mathrm{B}}{\mathrm{D}}, \frac{\rho_{\mathrm{s}}}{\rho}=\mathrm{G}_{\mathrm{s}}, \frac{\mathrm{d}_{50}}{\mathrm{~d}_{0}}, \frac{\mathrm{K}_{\mathrm{r}}}{\mathrm{d}_{0}}\right.$,

$$
\left.\sigma_{\mathrm{g}}, \frac{\mathrm{t}}{\mathrm{t}_{\mathrm{e}}}, \frac{\mathrm{L}_{\mathrm{sx}}}{\mathrm{L}_{\mathrm{sy}}}, \frac{\mathrm{d}_{\mathrm{s}}}{\mathrm{d}_{\mathrm{s}_{\max }}}, \frac{1_{\mathrm{p}}}{\mathrm{d}_{0}}, \frac{1_{\mathrm{p}}}{\mathrm{b}_{\mathrm{p}}}\right)
$$

در معادله فوق عبارت اول عدد رينولدز بوده و براى دبسىهـاى لهاى

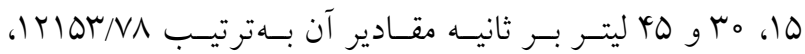

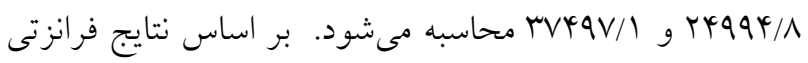

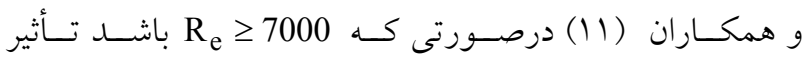

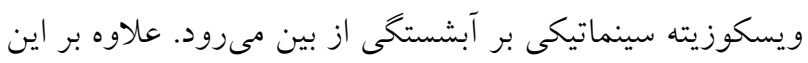

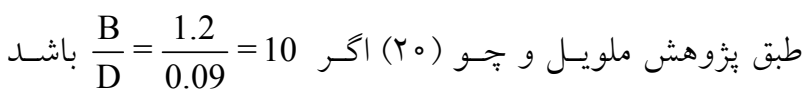
مىتوان از تأثير ديواره كانال بر عمق آبشستكى اطراف بإيههـاى

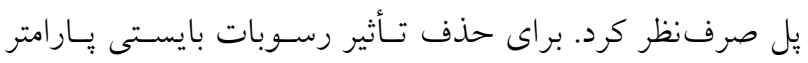

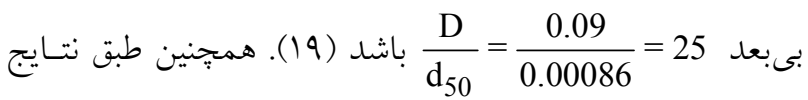
دى و همكاران (9) درصورتى كـه توزيـع رسـوبات يكنو اخــت

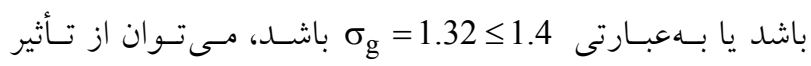

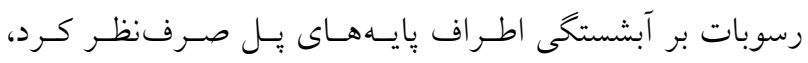

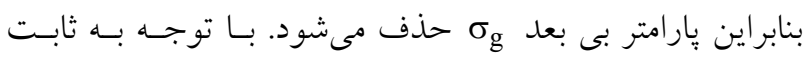

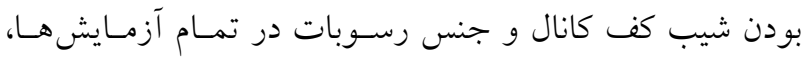

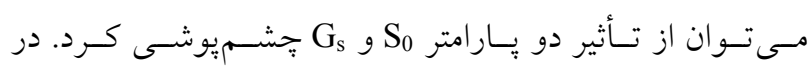

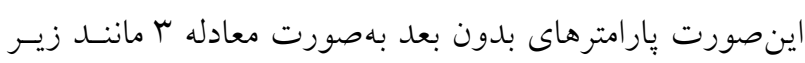
خلاصه مى شوند:

$\frac{d_{s}}{d_{s_{\max }}}=f\left(\frac{t}{t_{e}}, \frac{K_{r}}{d_{0}}, \frac{L_{s x}}{L_{s y}}, \frac{l_{p}}{b_{p}}\right)$

\section{نتايج و بحث}

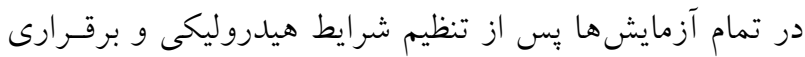
جريان در فلوم، گردابهها با سـرعت زيـادى در اطـراف بايسههـا

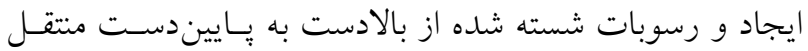

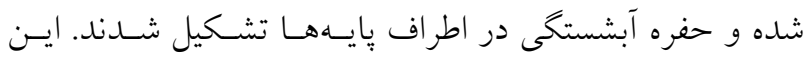
عمل تا جايى ادامه يافت كه جريان ديخر توانايى انتقال رسوبات

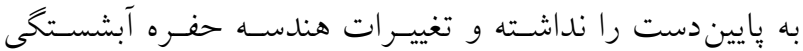




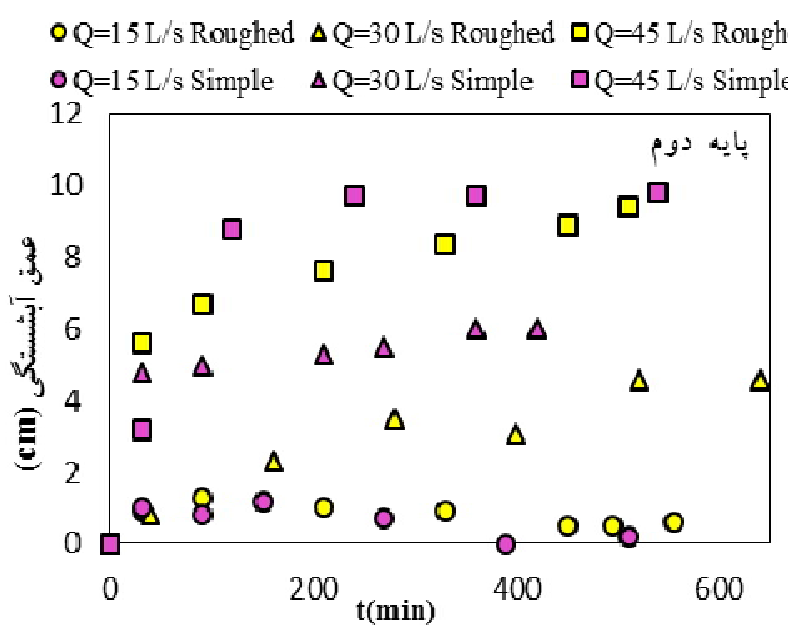

$\circ \mathrm{Q}=15 \mathrm{~L} / \mathrm{s}$ Roughed $\Delta \mathrm{Q}=30 \mathrm{~L} / \mathrm{s}$ Roughed $\mathrm{QQ}=45 \mathrm{~L} / \mathrm{s}$ Roughed $\circ \mathrm{Q}=15 \mathrm{~L} / \mathrm{s}$ Simple $\Delta \mathrm{Q}=30 \mathrm{~L} / \mathrm{s}$ Simple $\quad \mathrm{Q}=45 \mathrm{~L} / \mathrm{s}$ Simple

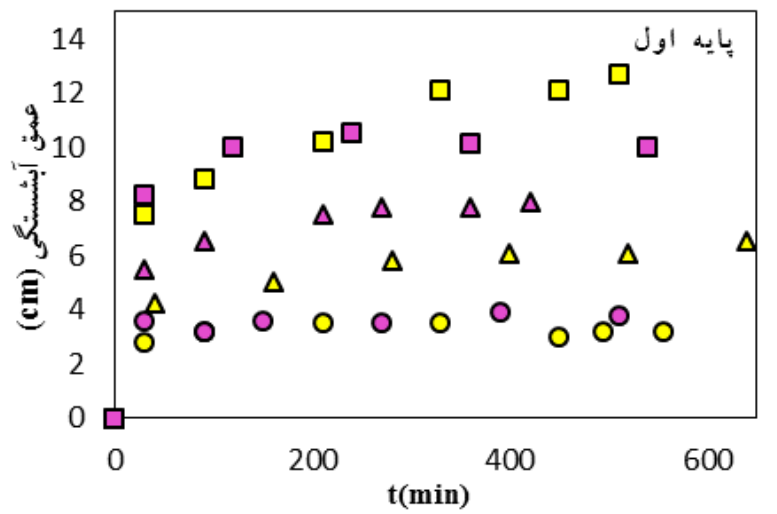

$\circ \mathrm{Q}=15 \mathrm{~L} / \mathrm{s}$ Roughed $\Delta \mathrm{Q}=30 \mathrm{~L} / \mathrm{s}$ Roughed $\mathrm{QQ}=45 \mathrm{~L} / \mathrm{s}$ Roughed ०Q $=15 \mathrm{~L} / \mathrm{s}$ Simple $\Delta \mathrm{Q}=30 \mathrm{~L} / \mathrm{s}$ Simple $\quad \mathrm{Q}=45 \mathrm{~L} / \mathrm{s}$ Simple

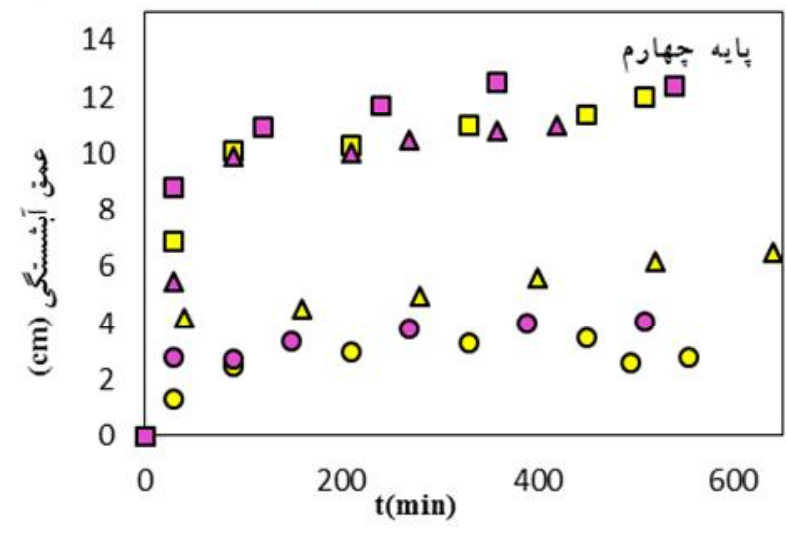

$\circ Q=15 \mathrm{~L} / \mathrm{s}$ Roughed $\Delta Q=30 \mathrm{~L} / \mathrm{s}$ Roughed $\square Q=45 \mathrm{~L} / \mathrm{s}$ Roughed

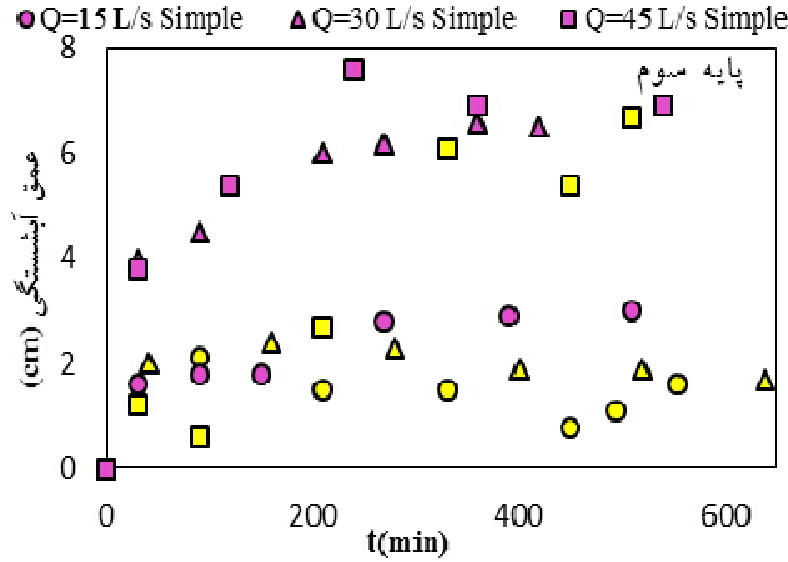

$\circ \mathrm{Q}=15 \mathrm{~L} / \mathrm{s}$ Roughed $\Delta \mathrm{Q}=30 \mathrm{~L} / \mathrm{s}$ Roughed $\square \mathrm{Q}=45 \mathrm{~L} / \mathrm{s}$ Roughed

$\circ Q=15 \mathrm{~L} / \mathrm{s}$ Roughed $\Delta \mathrm{Q}=30 \mathrm{~L} / \mathrm{s}$ Rou ghed $\square \mathrm{Q}=45 \mathrm{~L} / \mathrm{s}$ Roughed

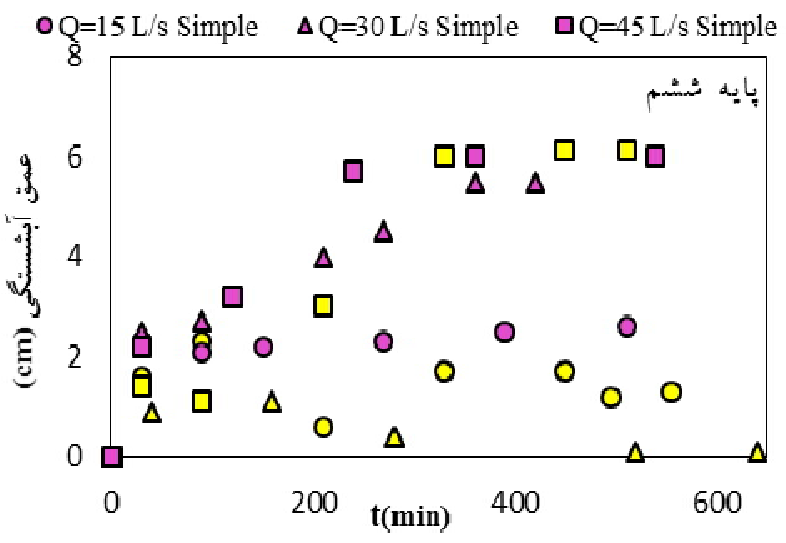
$\circ \mathrm{Q}=15 \mathrm{~L} / \mathrm{s}$ Simple $\Delta \mathrm{Q}=30 \mathrm{~L} / \mathrm{s}$ Simple $\quad \mathrm{Q}=45 \mathrm{~L} / \mathrm{s}$ Simple

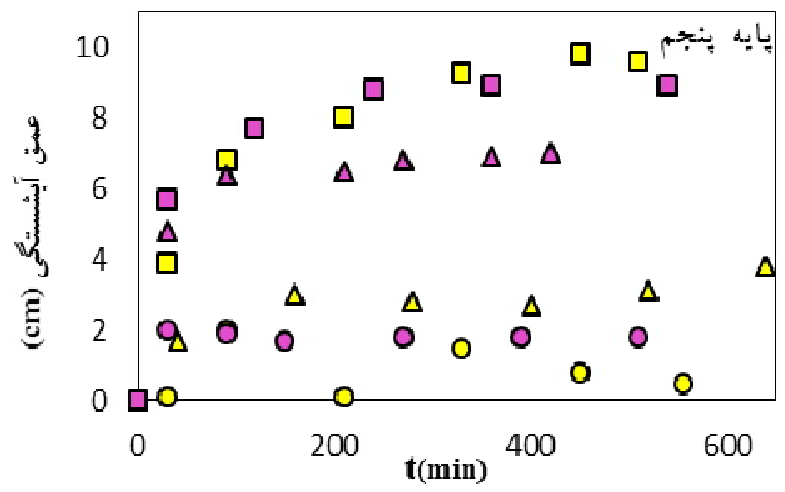

شكل r. تغييرات زمانى آبشستخى مقابل پايهها در دبىهاى مختلف براى تمام پايهها (رنخى در نسخه الكترونيكى) 
جدول r. زمان تعادل عمق آبشستخى براى تمام پِايهها برحسب دقيقه

\begin{tabular}{|c|c|c|c|c|c|c|c|}
\hline بِايه ششم & بايه بِنجم & بايه جهارم & بِايه سوم & بِايه دوم & يايه اول & مدل بِيه & دبى جريان (L/s) \\
\hline$r q o$ & س & $Y Q \circ$ & ח & 40 & TIO & زبر & \\
\hline 苜 & TVO & $r q 0$ & rVo & $r q 0$ & 100 & ساده & 10 \\
\hline 90 & 9० & 90 & 90 & 90 & 90 & تغييرات & \\
\hline$\Delta Y_{0}$ & 940 & 940 & Yoo & Oro & 940 & زبر & \\
\hline rqo & KYo & KYo & reo & rqo & YYo & ساده & r。 \\
\hline 190 & rYo & rro & ro & 190 & Tro & تغييرات & \\
\hline م" & $\Delta Y_{0}$ & $01 \circ$ & $01 \circ$ & 010 & م" & زبر & \\
\hline rYo & $40 \circ$ & rqo & ra. & reo & rYO & ساده & id \\
\hline 90 & 90 & $10 \circ$ & $10 \circ$ & 100 & 90 & تغييرات & \\
\hline
\end{tabular}

جدول r. ميزان كاهش عمق آبشستخى مدل زبر نسبت به ساده در مقابل پايهها در زمان تعادل

\begin{tabular}{|c|c|c|c|c|c|c|}
\hline مقابل بِيايه ششم & مقابل يِايه ينجم & مقابل بِايه جهارم & مقابل بِياه سوم & مقابل پِايه دوم & مقابل پيايه اول & \\
\hline$-1 / \mu$ & $-1 / \mu$ & $-1 / \mu$ & $-1 / 4$ & $0 / 4$ & $-0 / 9$ & 10 \\
\hline$-Q / \uparrow$ & $-r / r$ & $-Y / D$ & $-\psi / \Lambda$ & $-1 / 4$ & $-1 / 0$ & $\mu_{0}$ \\
\hline$-0 / 1$ & $-\circ / V$ & $-0 / 4$ & $-0 / T$ & $-0 / 4$ & $T / V$ & iQ \\
\hline
\end{tabular}

جدول f. ميزان كاهش عمق آبشستخى مدل زبر نسبت به ساده در پشت پايهها در زمان تعادل

\begin{tabular}{|c|c|c|c|c|c|c|}
\hline يشت پيايه ششم & يشت بِيه ينجم & يشت يُايه جهارم & بشت پِايه سوم & يشت يّايه دوم & يشت پِايه اول & \\
\hline$-\circ / \mu$ & $-0 / T$ & $-0 / 9$ & $r / \Lambda$ & $1 / V$ & $-1 / 4$ & 10 \\
\hline$-Y / V$ & $-Y / r$ & $-r / \Lambda$ & $T / Y$ & $-Y / 4$ & $-1 / 4$ & $\mu_{\circ}$ \\
\hline$-0 / 4$ & $-1 / 9$ & $-0 / 9$ & $-0 / \wedge$ & $-0 / 0$ & $0 / \Lambda$ & id \\
\hline
\end{tabular}

اين دبى تمام مقادير عمق آبشستخى كاهش يافته است. مقايسـه نتايج مربوط به بالادست و بايين دست كودال برداشـت مصـالح نشان مىدهد كه گروه يايه هاى بل پاييندست بيشتر تحت تـأثير اعمال زبرى قرار گرفتهاند.

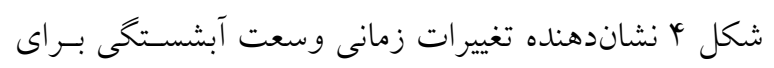
سه دبى هأ، هب و ها ليتر بر ثانيه است. مشـاهده مسىشـود كـه حداكثر وسعت آبشستخى هم در جهت طولى و هـم در جهـت

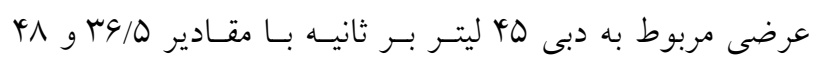

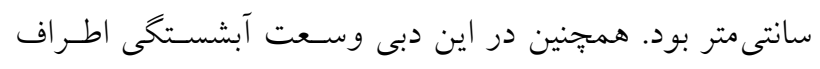

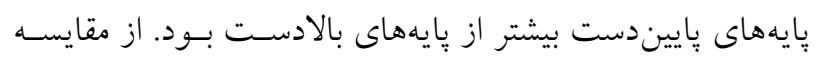

جدول بو و بيانكر ميزان تغييرات عمـق آبشستخى مــل زبــر نسبت به مدل ساده در مقابل و يشـت پيايسههـا در زمـان تعـادل

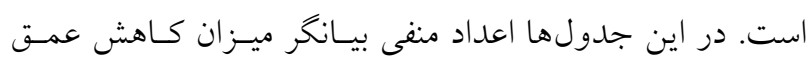
آبشستخى زمان تعادل در مدل زبر نسبت به مــدل سـاده اسـت.

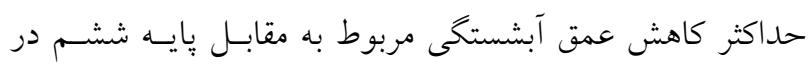

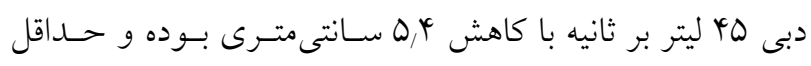

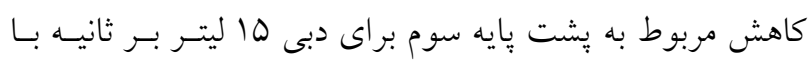

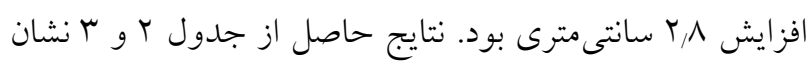
مىدهد مطلوبترين نتايج يس از اعمال زبرى بر سطح پيايه يـل

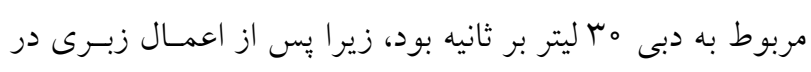



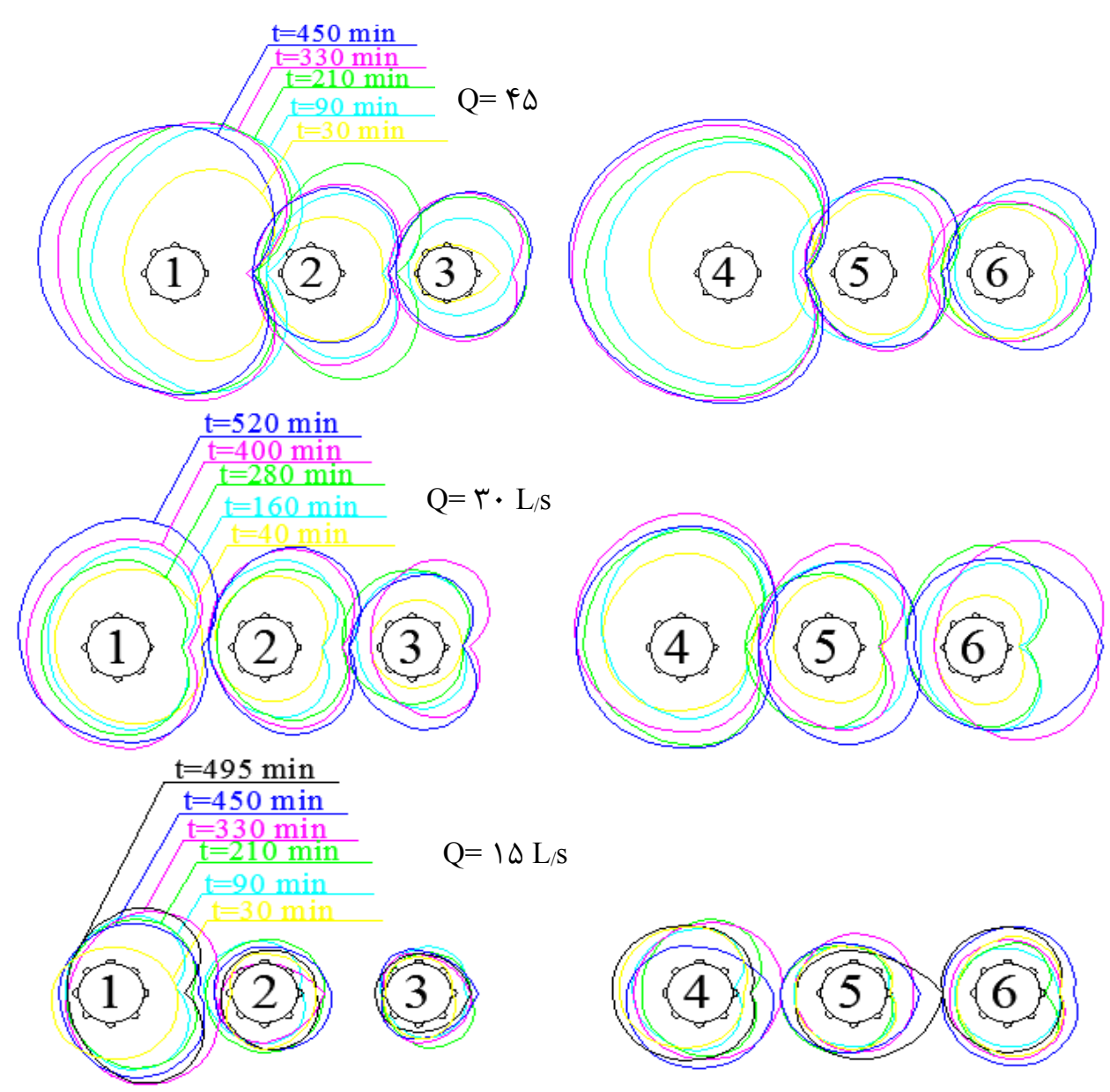

شكل ץ. تغييرات زمانى وسعت آبشستخى اطر اف گروه پايههاى بِل بالادست و پاييندست گودال برداشت مصالح در دبىهاى مختلف

$$
\text { (رنخى در نسخه الكترونيكى) }
$$

يايه إبهعنوان مانع در برابـر جريـان عمـل كـرده و سـبب كـاهش

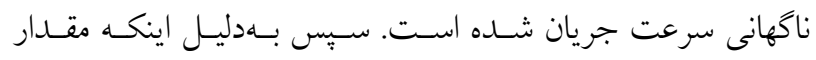

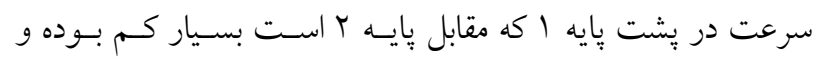

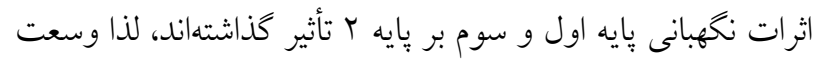

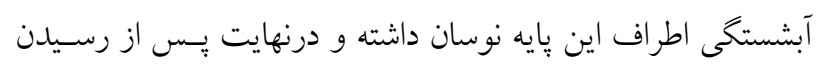
به زمان تعادل اين نوسانات منقطع شدهاند.

تأثير دبى جريـان بـر وسـعت آبشسـتخى بسـتر در انتهـاى

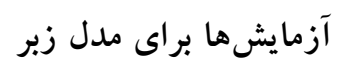

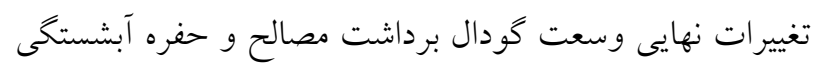

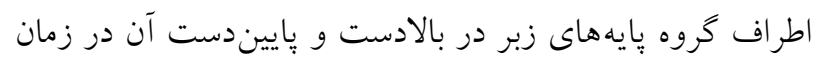

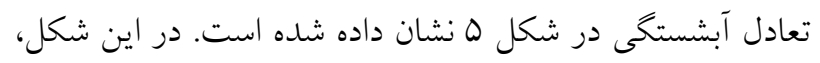

سه نمودار نتيجه گيرى شد كه با افزايش دبى وسعت آبشستـى نيـز

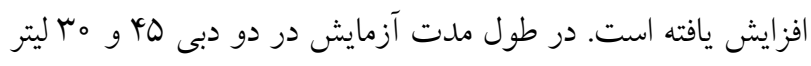

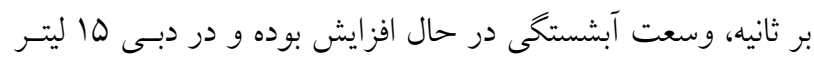

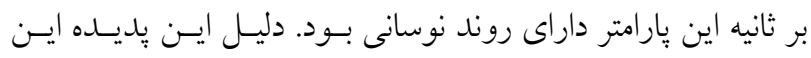

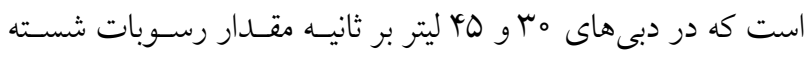

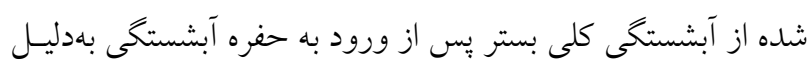

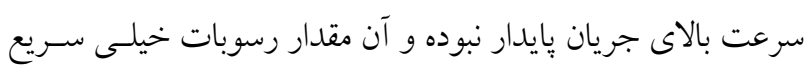

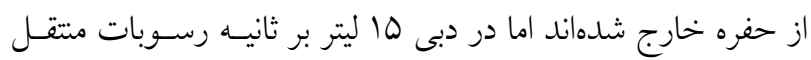

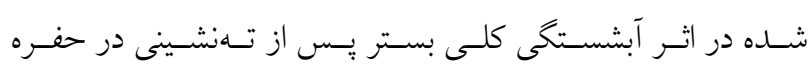

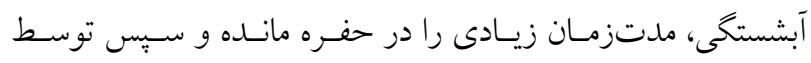

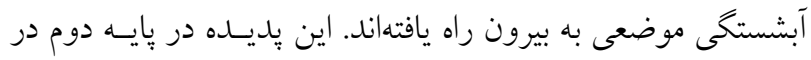

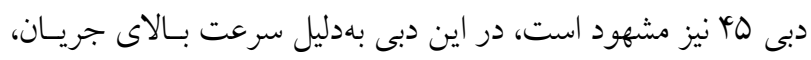




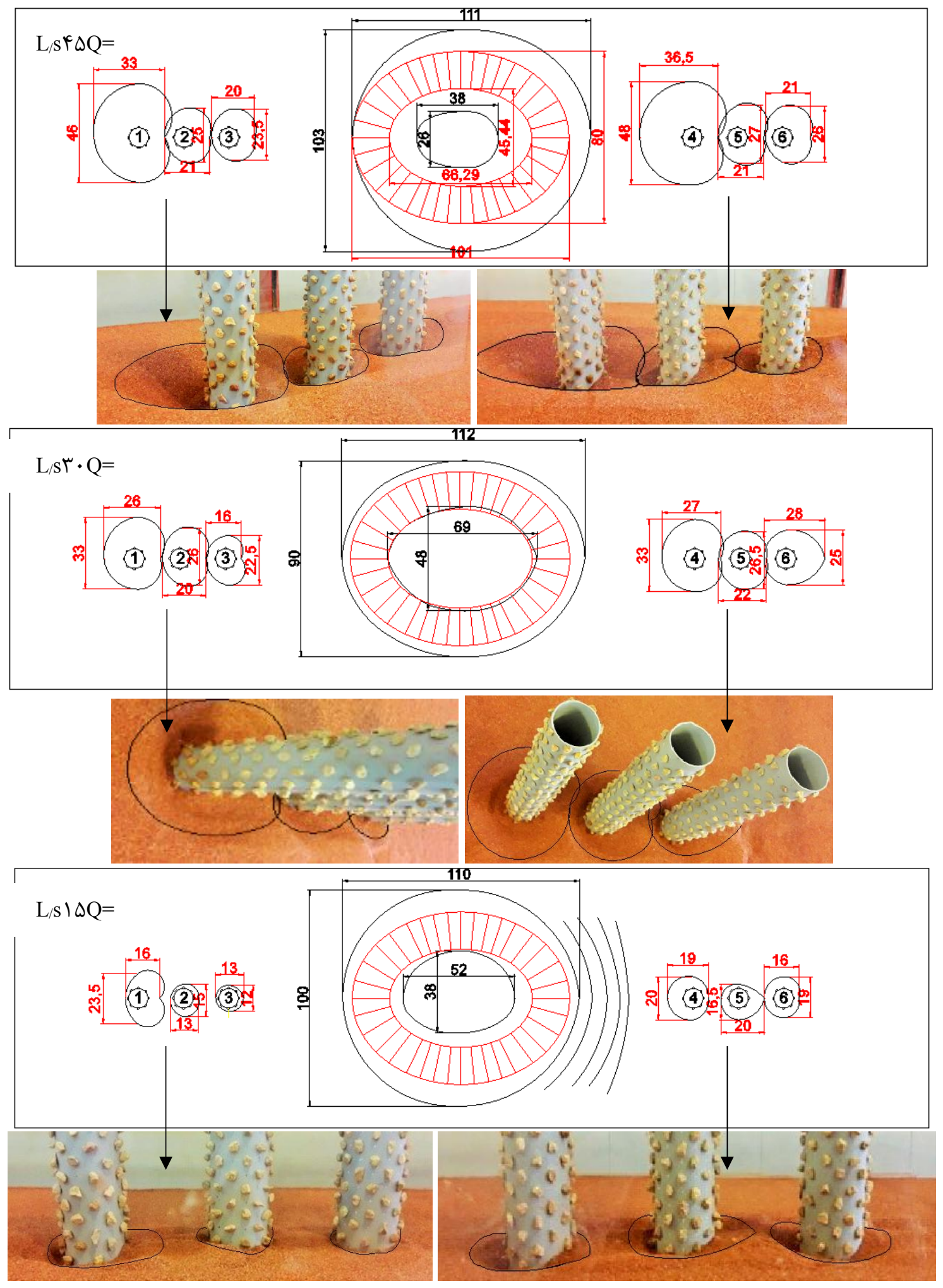

شكل ه. يلان بستر و وسعت حفره آبشستكى در زمان تعادل آبشستكى براى دبىهاى مختلف 


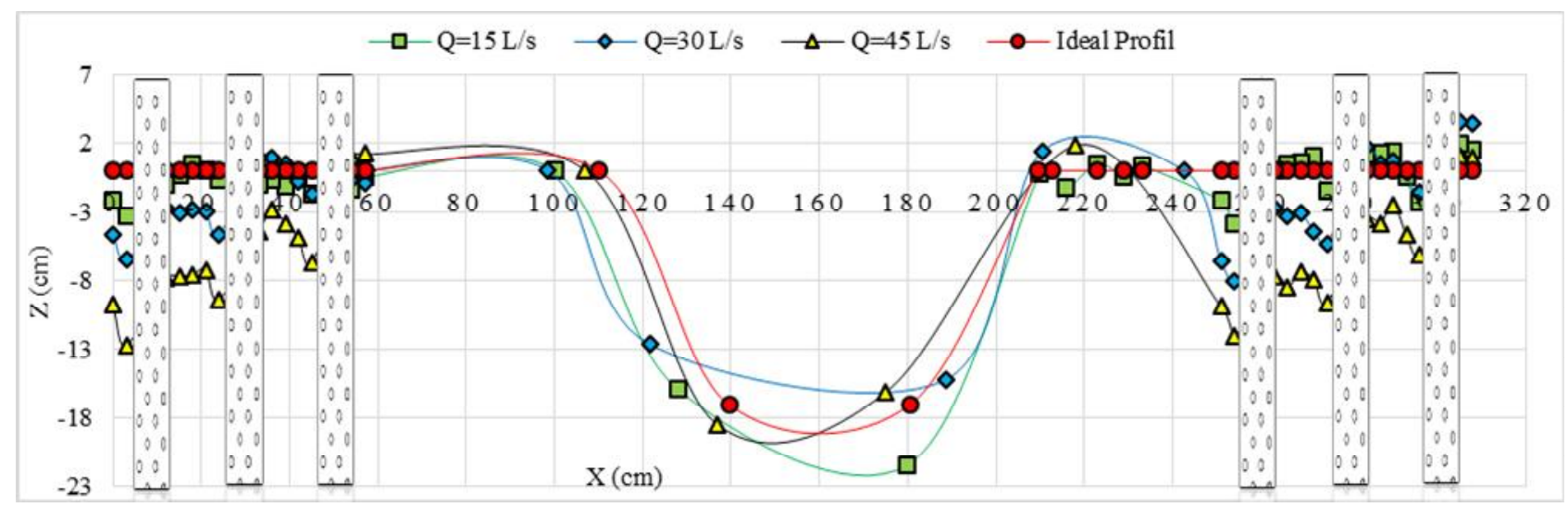

شكل 9. تأثير دبى جريان بر بروفيل طولى بستر در مدل زبر (رنكى در نسخه الكترونيكى)

افزايش وسعت آبشستكى را در جهت طولى كانـال شـاهد هستيم.

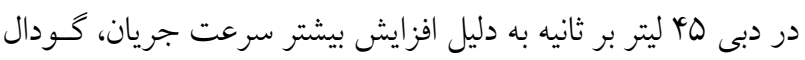

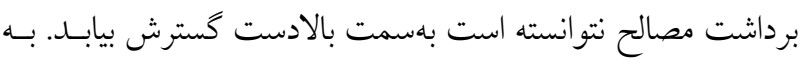

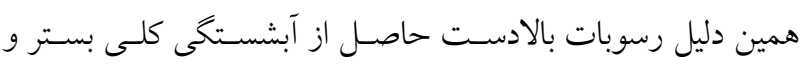

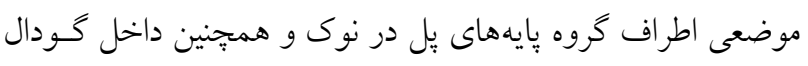
برداشت مصالح تهنشين شده است.

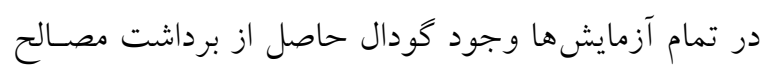
محلى را فراهم كرده است تاعمق جريان افزايش يافته و بهدليل

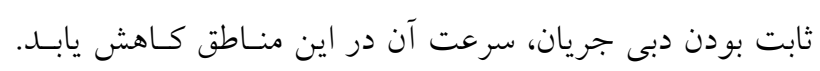

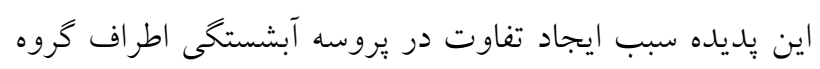

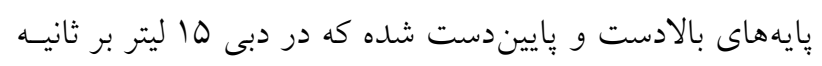

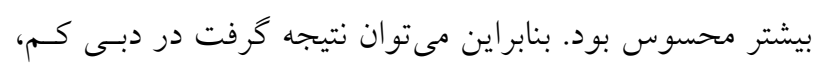

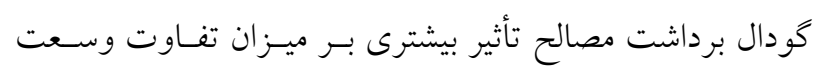

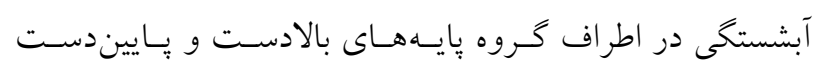

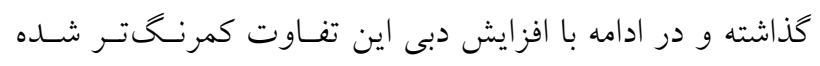

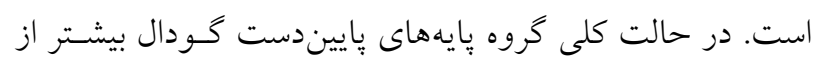

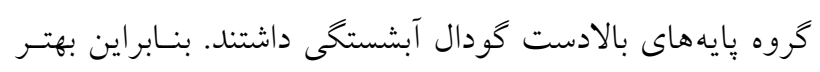

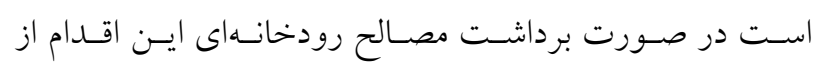
پاييندست گروه بايهها صورت كيرد.

تأثير دبى جريان بر بروفيل طولى بستر در مدل زبر

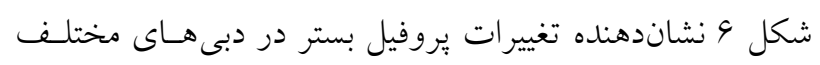

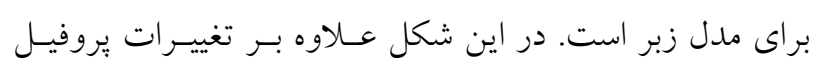

كودال قرمز رنخ، مربوط به گودال برداشـت مصـالح قبـل از شـروع

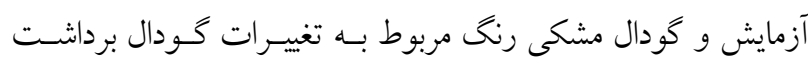

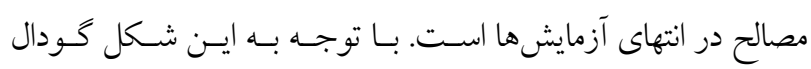

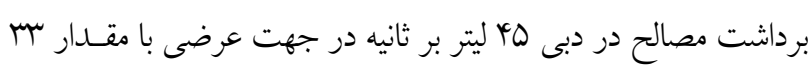

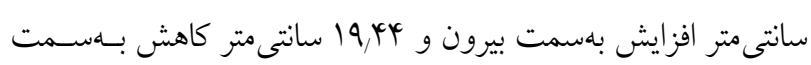

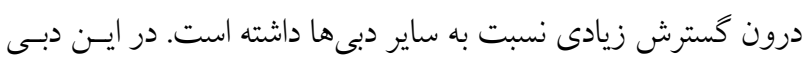

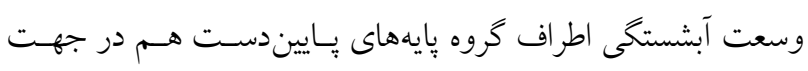

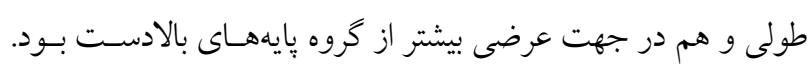

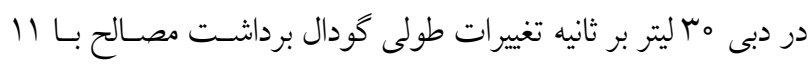

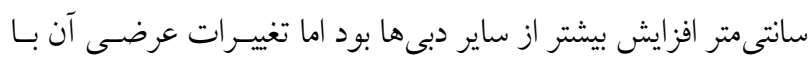

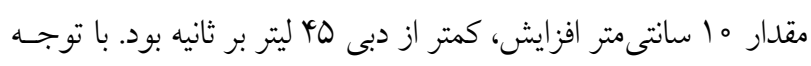

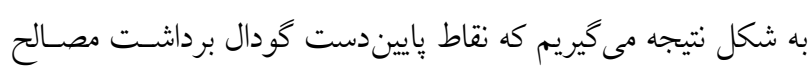

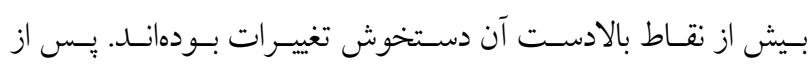

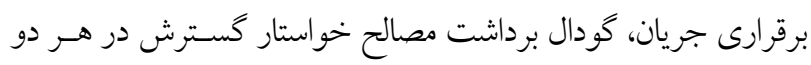
جهت طولى و عرضى بوده است. در دبسى 10 اليتـر بـر ثانيـه كـودال

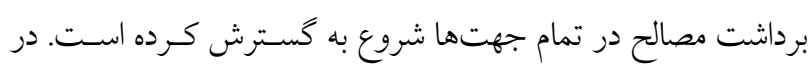

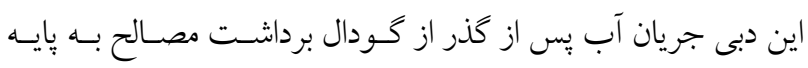

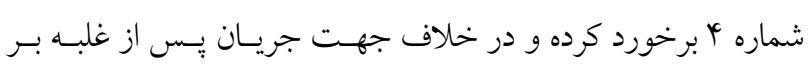

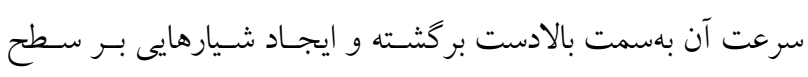

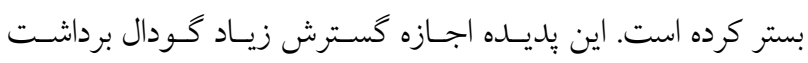

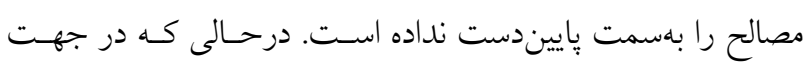

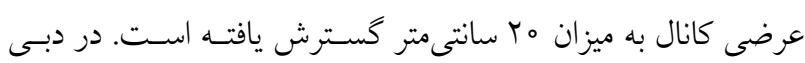

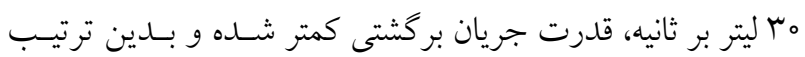




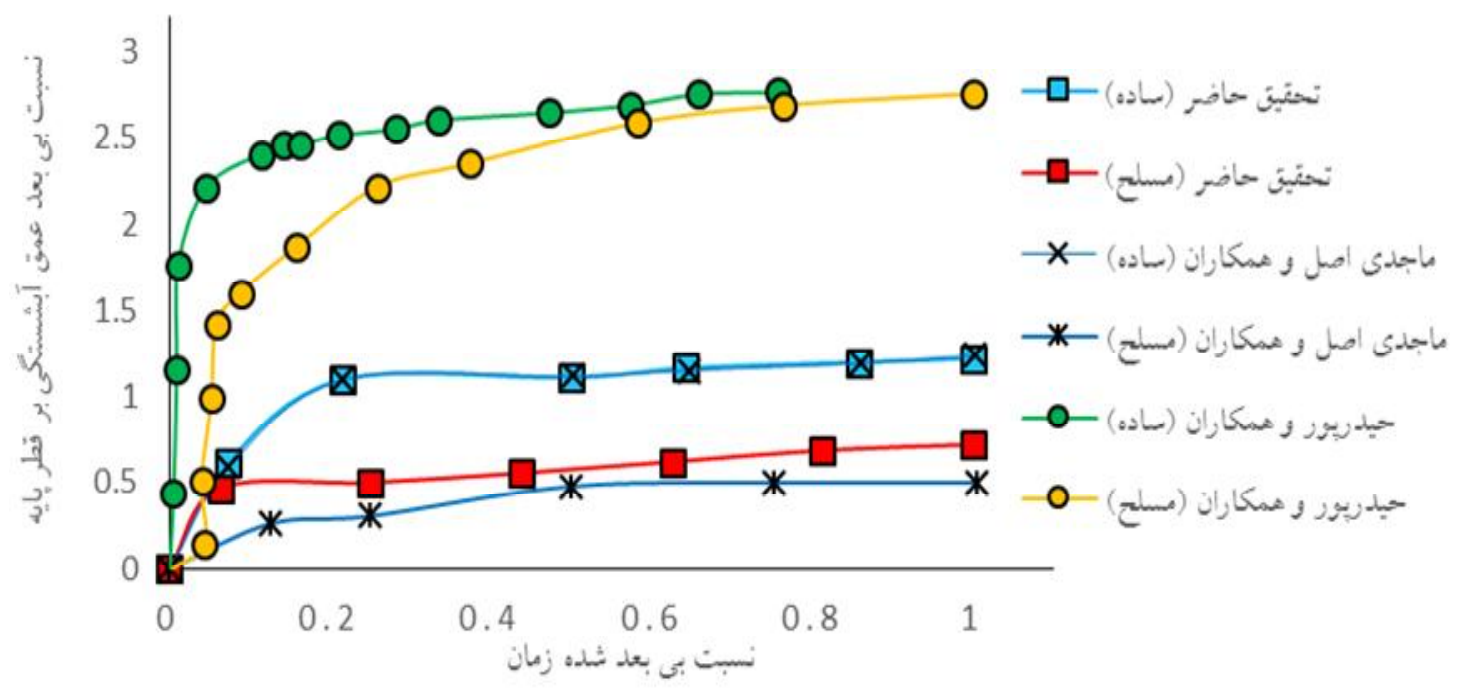

شكل v. مقايسه منحنى توسعه زمانى آبشتنى تحقيق حاضر و ساير محققين براى حداكثر عمق آبشستخى (رنخى در نسخه الكترونيكى)

(IV) و حيدريور و همكاران (IO) براى مقايسـه استفاده شـده

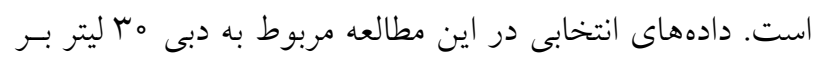

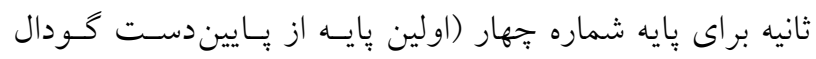

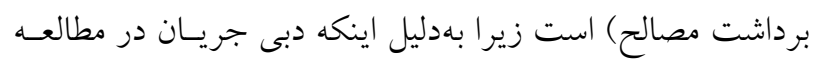

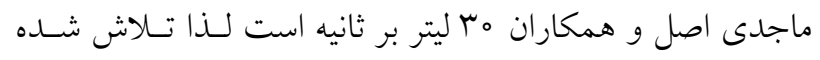

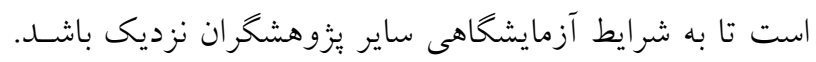

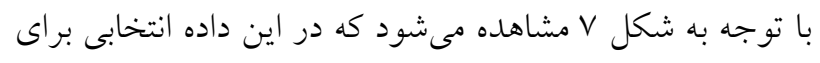

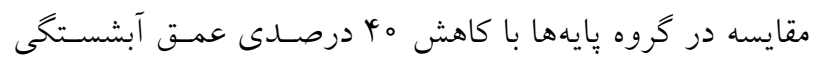
نتايج مطلوب ترى در مقايسه بـا مطالعـه حيــريور و همكـاران

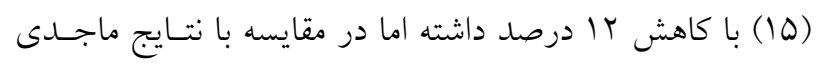

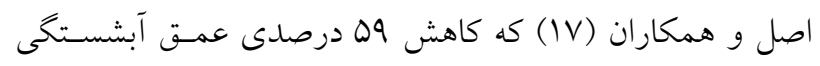

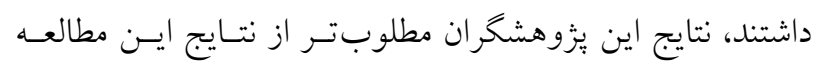

\section{نتيجه كيرى كلى}

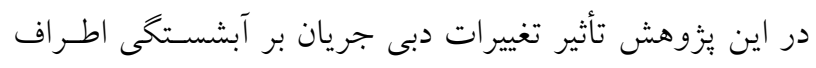

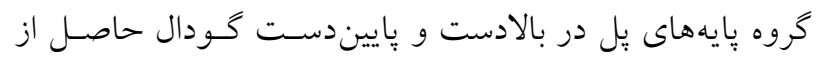

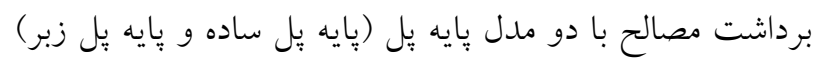

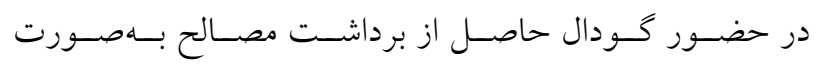

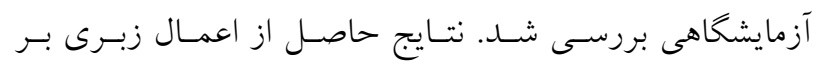

بستر در زمان اتمام آزمايشها، تغييرات بِروفيـل طـولى كـودال

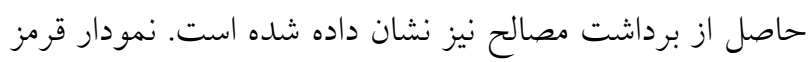

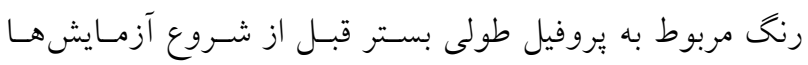

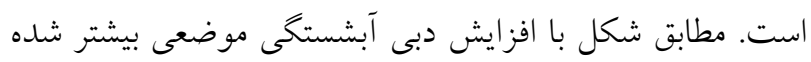

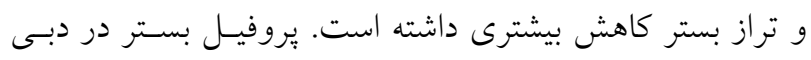

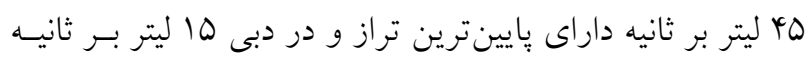

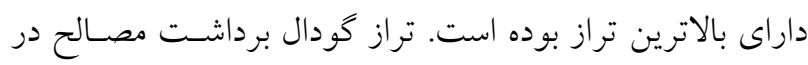

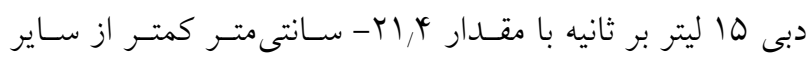

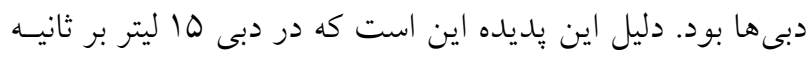

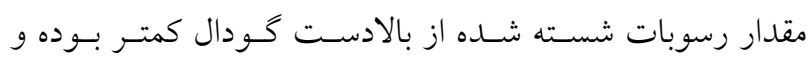

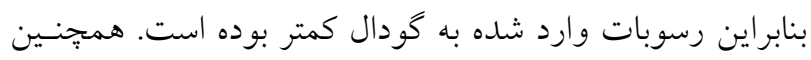
بهدليل اينكه سرعت جريان در دبى ها ليتر بر ثانيه كمتر از ساير

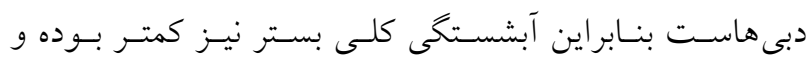
تغييرات كودال برداشت مصالح كمتر از ساير دبى ها بود.

مقايسه نتايج حاصل از اين مطالعه با نتايج ساير بزُوهشكران

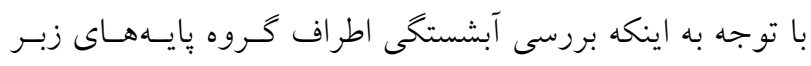

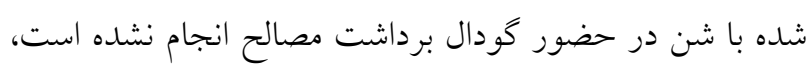

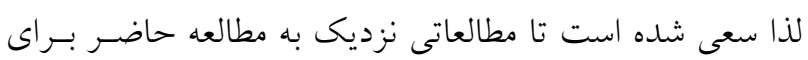

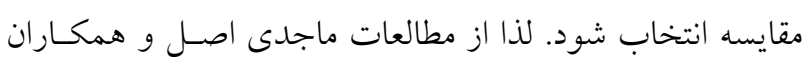




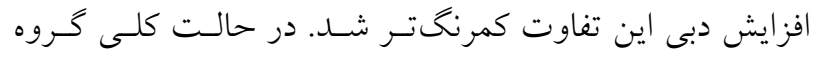

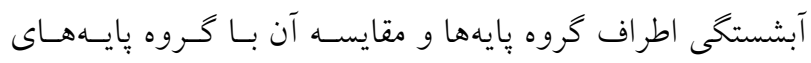

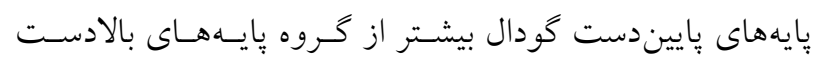

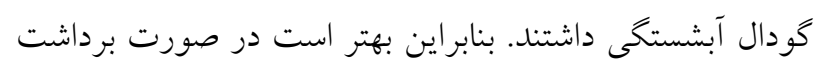

$$
\begin{aligned}
& \text { مصالح رودخانهاى علاوه بر رعايت ضـوابط فنسى ايسن اقـدام از }
\end{aligned}
$$

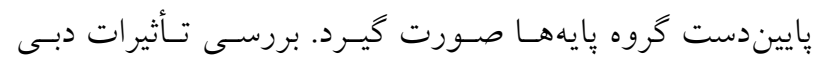

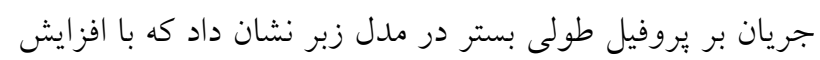

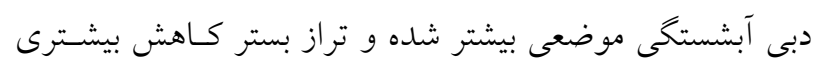

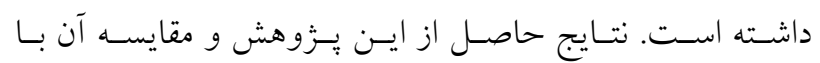

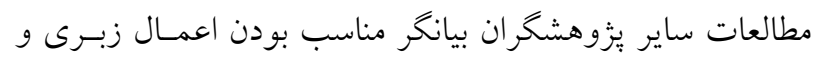

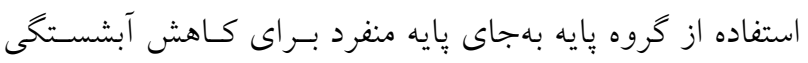

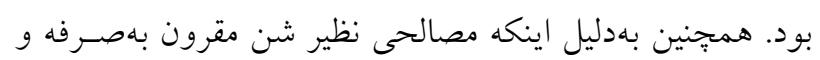

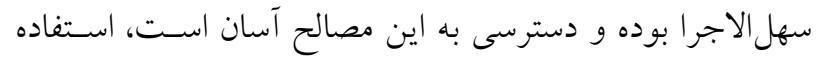

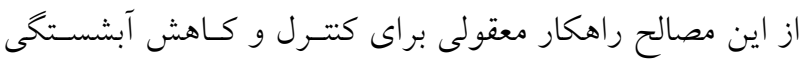

$$
\begin{aligned}
& \text { موضعى اطراف بايهها است. }
\end{aligned}
$$

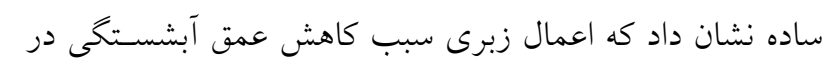

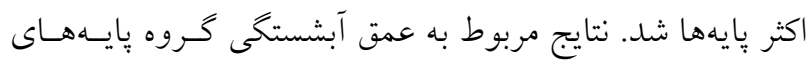

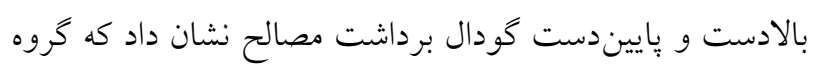

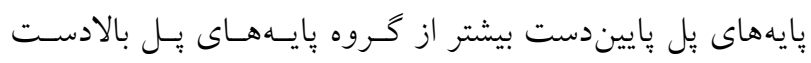

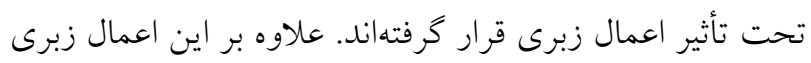

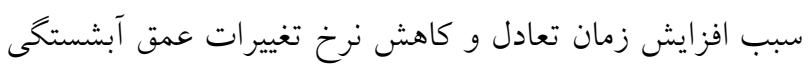

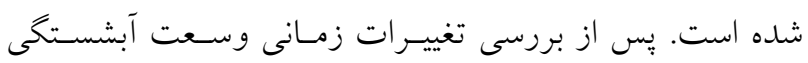

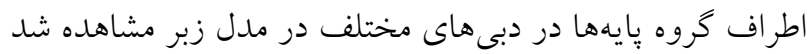

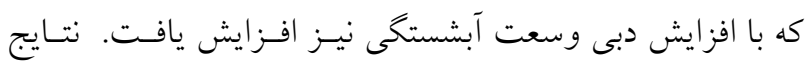

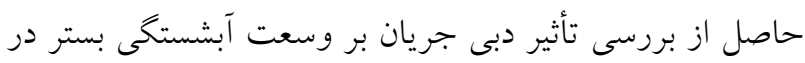

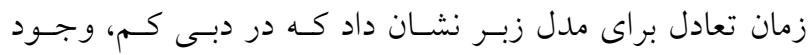

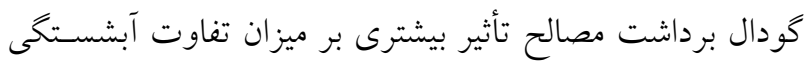

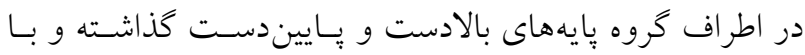

1. Ataie-Ashtiani, B. and A. A. Beheshti. 2006. Experimental investigation of clear-water local scour at pile groups. Journal of Hydraulic Engineering 132(10): 1100-1104.

2. Bozkuş, Z., M. C. Özalp and A. E. Dinçer. 2018. Effect of pier inclination angle on local scour depth around bridge pier groups. Arabian Journal for Science and Engineering 43(10): 5413-5421.

3. Chiew, Y. M. and B. W. Melville. 1987. Local scour around bridge piers. Journal of Hydraulic Research 25(1): $15-$ 26.

4. Daneshfaraz, R., J. Chabokpour, M. Dasineh and A. Ghaderi. 2019. The experimental study of the effects of river mining holes on the bridge piers. Iranian Journal of Soil and Water Research 50(7): 1619-1633. (In Farsi).

5. Daneshfaraz, R., J. Chabokpour and M. Dasineh. 2019. The experimental investigation of the maximum depth and length of the created pit holes due to the bed material removal under subcritical flow condition. Journal of Water and Soil Conservation 26(1): 111-130. doi: 10.22069/jwsc.2019.14817.2986. (In Farsi).

6. Daneshfaraz, R., J. Chabokpour and H. Nezafat. 2019. Experimental investigation of the scouring due to hydraulic jump in screens. Iranian Journal of Soil and Water Research 50(5): 1039-1051. doi: 10.22059/ijswr.2018.251621 .667846. (In Farsi).

7. Daneshfaraz, R., S. Sadeghfam and A. Tahni. 2019. Experimental investigation of screen as energy dissipators in the movable-bed channel. Iranian Journal of Science and Technology, Transactions of Civil Engineering 44: 12371246.

8. Davodi, H., A. R. Masjedi, M. Heidarnejad, A. Bordbar and A. A. Kamanbedast. 2019. Investigation of the effect of cable on the control of scour around the piles group in the river. Journal of Hydrology and Soil Science 23(2): 7386. magiran.com/p2024496. (In Farsi).

9. Dey. S., S. K. Bose and G. L. N. Sastry. 1995. Clear Water Scour at Circular Piers: a model. Journal of Hydraulic Engineering 121(12): 869-876.

10. EL-Ghorab, E. A. 2013. Reduction of scour around bridge piers using a modified method for vortex reduction. Alexandria Engineering Journal 52(3): 467-478.

11. Franzetti, S., S. Malavasi and C. Piccinin. 1994. sull'erosione alla base pile di ponte in acquechiare. Proc., XXIV Convegno di Idraulica e Costruzioni Idrauliche 2: T4 13-24. (in Italian).

12. Ghafouri, A., M. Mohammadi Davoodi and E. Amiri Teklodani. 2019. Effects of sand cavity harvesting on river bed profiles. 6th National Congress of Civil Engineering, Semnan, Semnan University, https://www.civilica.com/Paper - 
NCCE06-NCCE06_1050.html. (In Farsi).

13. Guemou, B., A. Seddini and A. N. Ghenim. 2018. Scour around bridge piers: numerical investigations of the longitudinal biconcave pier shape. Periodica Polytechnica Mechanical Engineering 62(4): 298-304.

14. Haghnazar, H., R. Aminineghad and M. Saneie. 2018. Experimental study of the Location and type of pits extraction on the management of bed materials mining. Iranian Journal of Soil and Water Research 49(1): 221 - 231. (In Farsi).

15. Heidarpour, M., H. Afzalimehr and E. Izadinia. 2010. Reduction of local scour around bridge pier groups using collars. International Journal of Sediment Research 25(4): 411-422.

16. Lou, X., L. Cheng, Z. Chen, G. Tang and F. Yang. 2019. The effect of Reynolds number on local scour around a monopile. In International Conference on Asian and Pacific Coasts. Springer, Singapore.

17. Majedi Asl, M., R. Daneshfaraz and S. Valizadeh. 2019. Experimental investigation of the river materials mining effect on the scouring around armed pier groups. Iranian Journal of Soil and Water Research 50(6): 1363-1380. doi: 10.22059/ijswr.2019.269942.668062. (In Farsi).

18. Malik, R., and B. Setia. 2020. Interference between pier models and its effects on scour depth. SN Applied Sciences 2(1): 68 .

19. Melville, B. W. and A. J. Sutherland. 1988. Design method for local scour at bridge piers. Journal of Hydraulic Engineering 114(10): 1210-1226.

20. Melville, B.W. and Y. M. Chiew. 1999. Time scale for local scour at bridge piers. Journal of Hydraulic Engineering 125(1): 59-65.

21. Memar, S., M. Zounemat-Kermani, M. Zahimpour, A. Beheshti and A. Schleiss. 2019. An investigation on the impacts of the skew angle on two bridge piers with respect to the flow direction on the equilibrium scour depth at the piers front. Journal of Hydraulics 14(1): 107-121. doi: 10.30482/jhyd.2019.153381.1334. (In Farsi).

22. Mohammed, Y. A., Y. K. Saleh and A. A. M. Ali. 2015. Experimental investigation of local scour around multivents bridge piers. Alexandria Engineering Journal 54(2): 197-203.

23. Raudkivi, A. J. and R. Ettema. 1983. Clear-water scour at cylindrical piers. Journal of Hydraulic Engineering 109(3): 338-350.

24. Rezaie, M., R. Daneshfaraz and M. Dasineh. 2018. Experimental investigation of adding clay and PAM on scour reduction bridge piers under the influence removal of river materials. Journal of Hydraulics 13(3): 59-70. doi: 10.30482/jhyd.2018.81358. (In Farsi).

25. Wu, P., R. Balachandar and A. Ramamurthy. 2018. Effects of splitter plate on reducing local scour around bridge pier. River Research and Applications 34(10): 1338-1346.

26. Zare, M. and T. Honar. 2016. The effect of groyne on reduction of the scour depth around bridge piers in river bends. JWSS-Isfahan University of Technology 19(74): 167-192. 


\title{
Experimental Investigation of the Effects of Flow Discharge on the Scour Rate around the Groups of Bridge Piers with a Rough Surface in the Presence of Aggregate Extraction Pits
}

\author{
R. Daneshfaraz*, M. Sattariyan Karajabad, B. Alinejad and M. Majedi As/ ${ }^{1}$
}

(Received: February 13-2020; Accepted: July 05-2020)

\begin{abstract}
The scour around the bridge piers is one of the main causes of bridge failure and the extraction of aggregates may aggravate this phenomenon. The present study comprehensively investigated the scour around the groups of bridge piers in the presence of aggregate extraction pits, using different discharges. The bridge piers roughened by gravel had been compared with the simple bridge piers; so, the results showed that the roughening caused the reduction of the scour depth. Scour depth change rate led to an increase in the equilibrium time. The results also showed that the reduction of the scour depth at the downstream groups of piers was more than that in the upstream. For the lowest discharge, the aggregate extraction pits had a considerable effect on the scour depth difference for the groups of piers in the downstream and upstream. On the other hand, the effects were decreased when the rate of discharge was increased. The experimental results obtained by the rough surface models showed that as the discharge was increased, the local scour was increased too; at the same time, the bed profile was posed at the low level. Generally, the scour depth of the groups of piers in the downstream of the extraction pit was more than that in the upstream. The results of the current research, therefore, demonstrated that the surface of the bridge pier roughened by gravel reduced the scour depth.
\end{abstract}

Keywords: Local scour, Bridge piers with rough surface, Aggregate extraction, Flow discharge, Bed profile

1. Department of Civil Engineering, Faculty of Engineering, University of Maragheh, Maragheh, Iran.

Corresponding author, Email: daneshfaraz@yahoo.com 